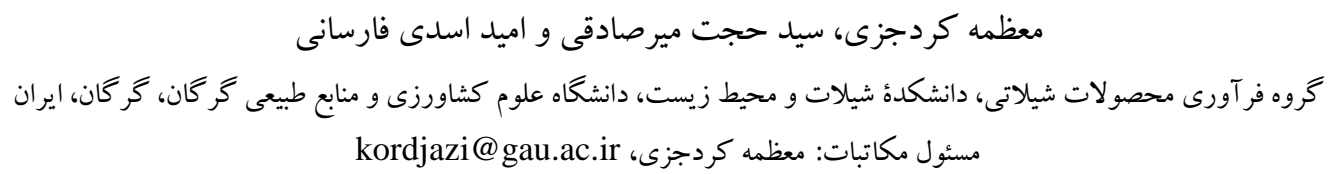

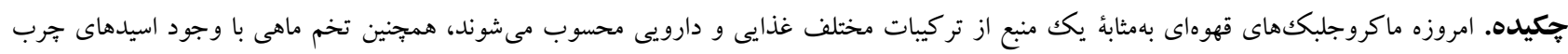

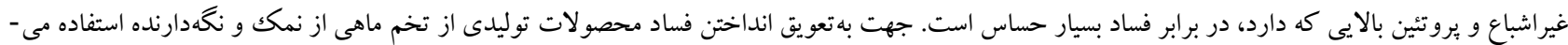

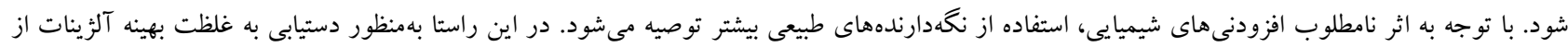

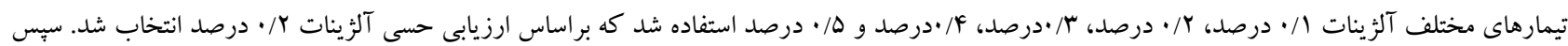

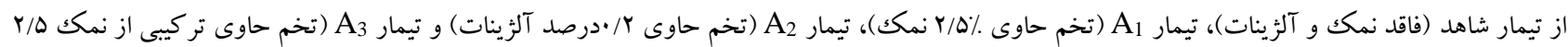

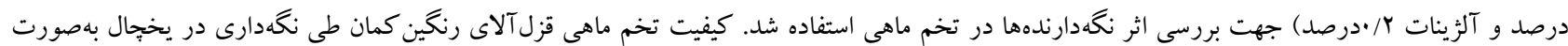

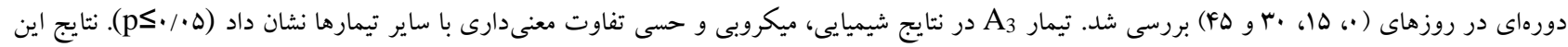

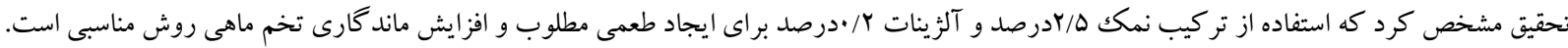
وازههاى كليدى. اسيد جرب، بلى ساكاريد جلبكى، شاخص هاى ميكروبى، فاكتورهاى فيزيكوشيميايى، ماند كارى ماهى

\title{
The effect of alginate extracted from brown algae Sargassum ilicifolium on the shelf life of rainbow trout roe
}

\author{
Moazameh Kordjazi, Seyed Hojjat Mirsadeghi, \& Omid Asadi Farsani \\ Seafood Processing Department, Faculty of Fisheries and Enviromental Sciences, Gorgan University of Agricultural \\ Sciences and Natural Resources, Gorgan, Iran \\ Correspondent author: Moazameh Kordjazi, kordjazi@gau.ac.ir
}

\begin{abstract}
Nowadays, brown macroalgae are considered to be a source of various nutritional and pharmaceutical compounds. In addition, fish roe is very susceptible to spoilage due to its high amount of protein and unsaturated fatty acids. In order to postpone the deterioration of roe-related products, salt and preservatives are utilized. Natural preservatives are recommended because of the adverse effects of chemical additives. Thus, different concentrations of pure alginate $(0.1 \%, 0.2 \%, 0.3 \%, 0.4 \%, 0.5 \%)$ were chose and then the $0.2 \%$ alginate was selected on the basis of the sensory evaluation of the results. Moreover, the treatments including control (salt-alginate-free), $\mathrm{A}_{1}$ (containing $2.5 \%$ salt) $\mathrm{A}_{2}$ (containing $0.2 \%$ alginate), $\mathrm{A}_{3}$ (containing $2.5 \%$ salt and $0.2 \%$ alginate) were used to investigate their preservative effects on fish roe. The quality of rainbow trout roe was assessed within $0,15,30,45$ days at refrigerated storage. The treatment $\mathrm{A}_{3}$ showed significant differences in microbial, chemical and sensory results compared with other treatments $(\mathrm{p} \leq 0.05)$. According to the results, salting $2.5 \%$ and alginate $0.2 \%$ method gave good flavor and increased shelf life to the roe.
\end{abstract}

Keywords. algae polysaccharide, fatty acide, microbial indices, physicochemical factors, shelf-life 
حسى و تغذيهاى در بازارهـاى داخلـى و بـين المللـى افزايش يافتـه است (Bledsoe et al., 2003) كه بيشتر به شكل دودى، كنسرو

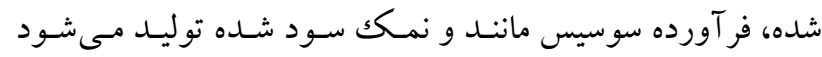

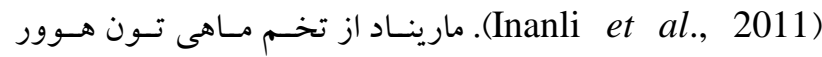
در ايران به صورت آزمايشى توليـد شـد و (Thunnus tonggol) تخم ماهيان استخو انى به ويزه ماهى كفال طلايس (Liza aurata) و ماهى سفيد (Rutilus frisii kutum) در سواحل جنوبى دريـاى خزر، با استفاده از آبنمكك مورد فر آورى قرار مى گيرد و يا بـدون نمك در تركيب با مواد ديخر در تهيه غذا استفاده مى مودد.

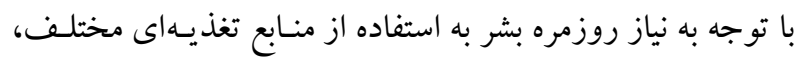

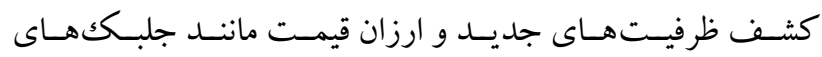

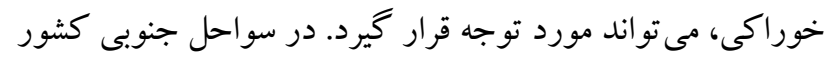

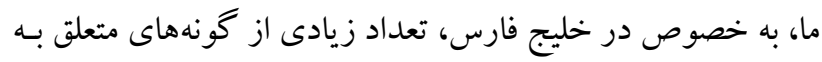

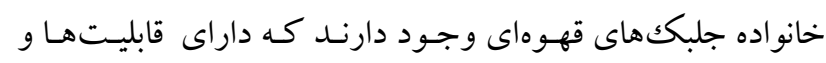
يتانسيلهاى زيادى هستند كه تحقيقات كمترى در زمينه استخراج

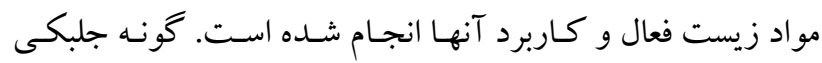
Sargassum ilicifolium از دسته جلبككهاى قهوهاى است كه. در سواحل شمالى خليج فارس به وفور يافت مىشود. بـا توجـه بـهـ

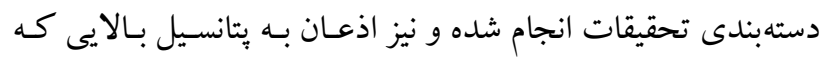

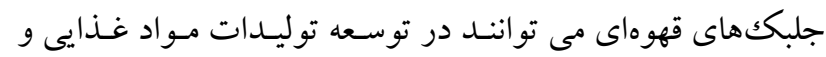

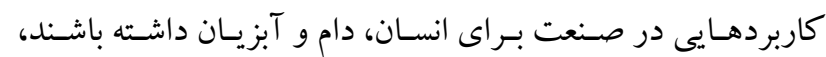

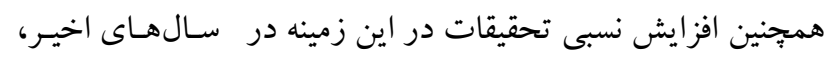
ضرورت انجام اين يزوهش هويدا مىشود.

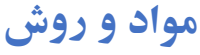

عصاره تيرى جلبكك مورد استفاده در اين تحقيق از سـواحل كـانى در جزيـره

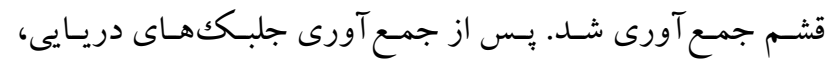

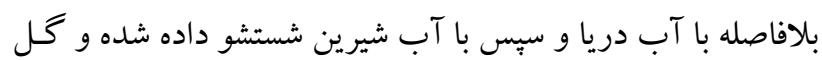

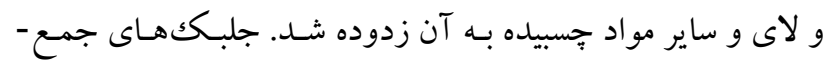

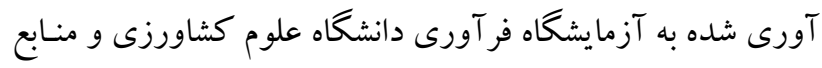

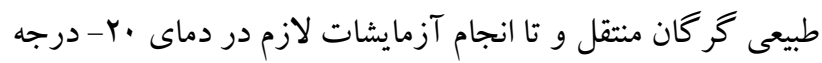

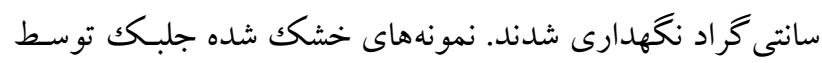

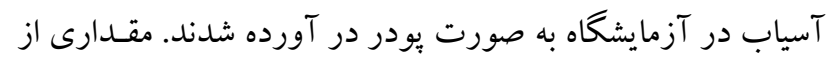

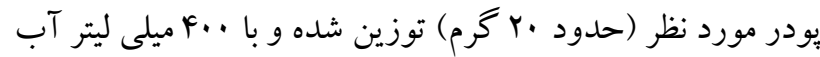

dollo

جلبك هاى دريايى، هم درصـد از كل توليد جهانى گياهـان آبزى را تشكيل مىدهند به همين دليل بهمنزلة يكى از بزر كترين توليد كنند كان دريا محسوب مىشود ( Meillisa et al., 2015). همجنين آنها يكى از منابع غنى از مواد معلنى، بروتئين، ويتامين،

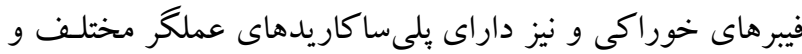

ضرورى بـراى تغذيـه انسـان هستيند ) Sakthivel \& Pandima, . (2015

آلزينات ها از يليمرهاى طبيعى جزء گروه يلمىسـاكاريدها هستيند

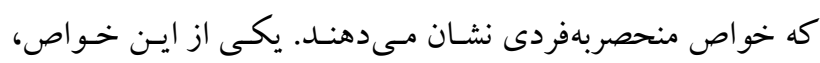

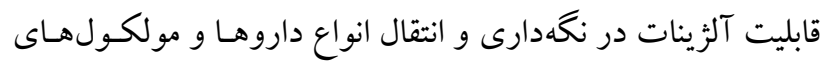

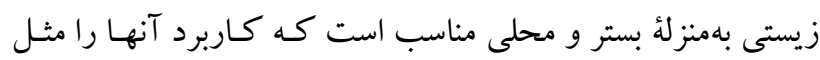

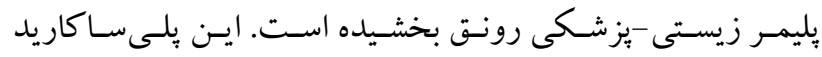

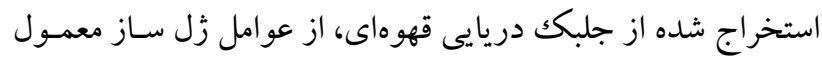

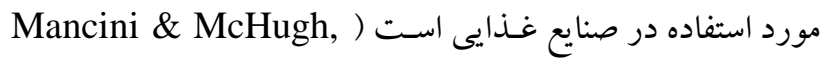

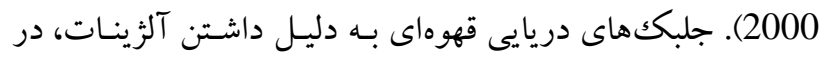

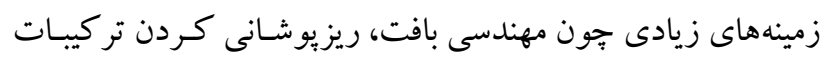
غذا-دارو و تهيه داروهاى خاص در علم بز شكى بكار مىروند و از اهميت اقتصادى زيادى برخوردارند (Sellimia et al., 2015).

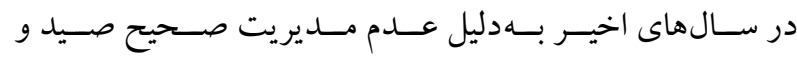
آلود گى هاى زيسـتمحيطى ناشى از فعاليـتهـاى انسـانى، ذخــاير

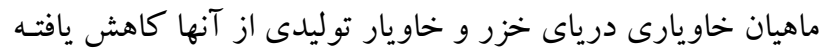

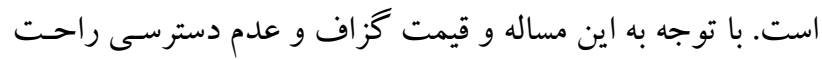

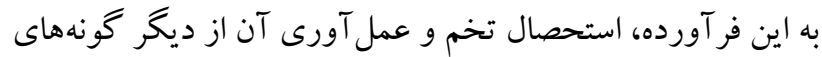
Majazi Amiri \& Rezaei ( مـاهى مناسب بـنظر مسىرســ (Tavabe, 2010; Bledsoe et al., 2003 از اسيدهاى جرب غير اشباع امگا-س، خصوصا دو كوزاهگز انوئيك-

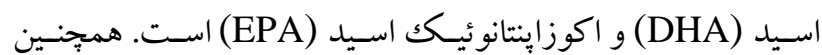

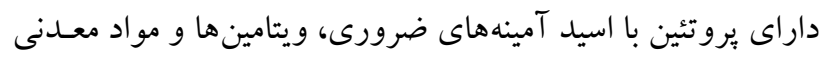

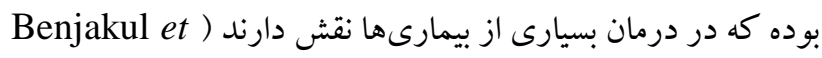
al., 2011; Kirzek et al., 2011

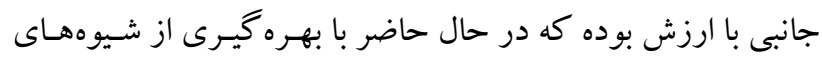

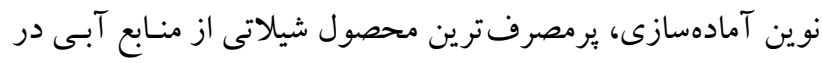

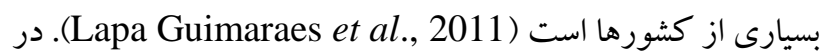

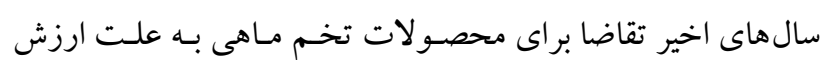




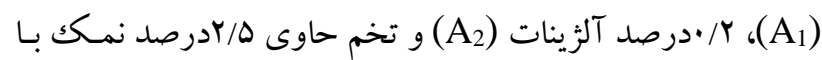

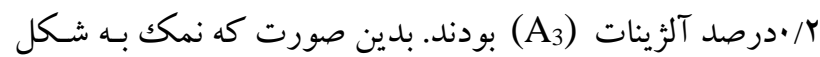

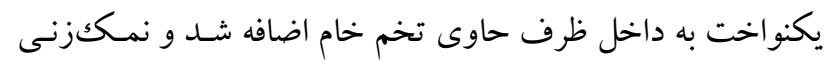

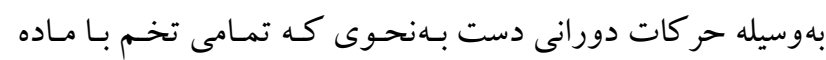

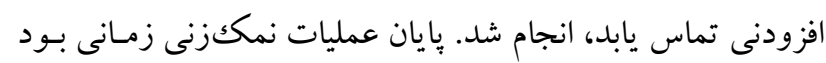

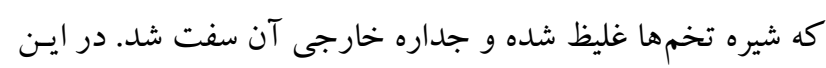

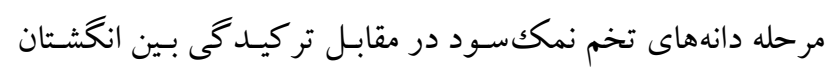

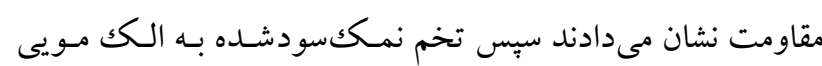

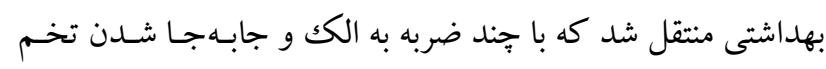

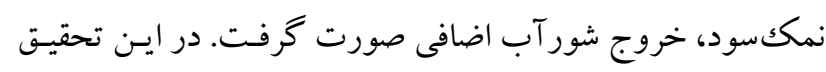

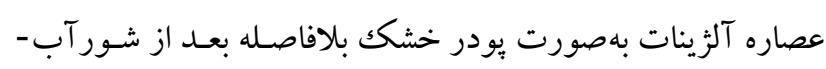
كيرى به تخم نمككسود اضافه شد. تخـم فر آورى شـده در بـ بايـان،

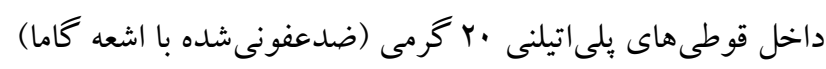

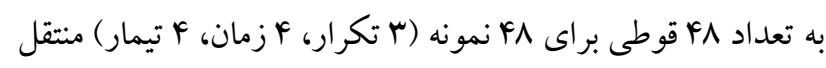

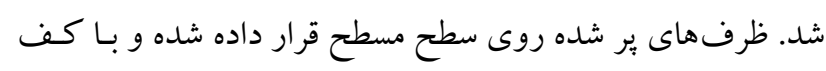

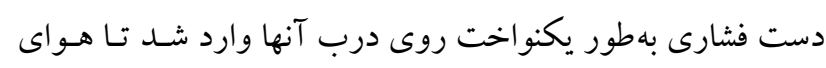

داخل قوطى خارج شود (Mirsadeghi et al., 2015).

\section{نمونهبردارى}

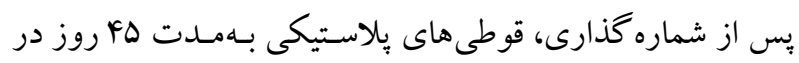

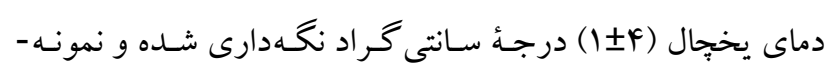
بردارى بهمنظور بررسى فاكتورهاى كيفى و اندازه خيرى اسيدهاى

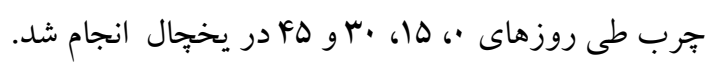

\section{اندازهيرى تر كيبات تقريبى}

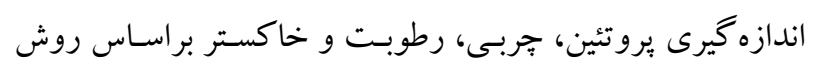

يروانه، (Parvaneh, 1998).

\section{اندازهيرى pH}

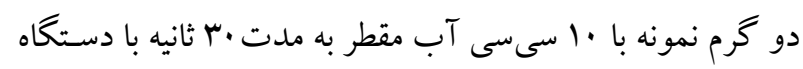

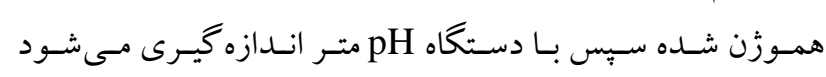

.(Sallam et al., 2004)

آزمايشات شيميايى

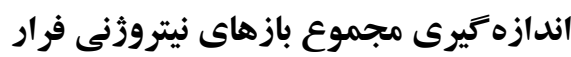

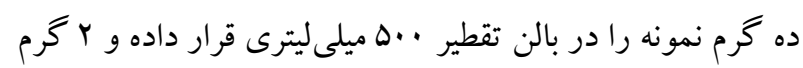

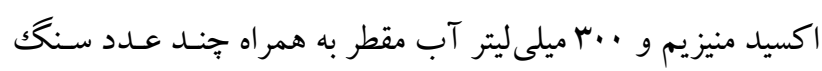

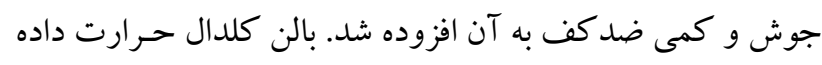

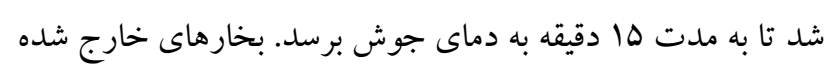

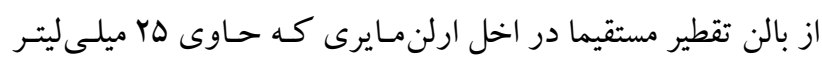

مقطر مخلوط، در فلاسك ته گرد .... ميلىليترى قرار گرفتنـد و

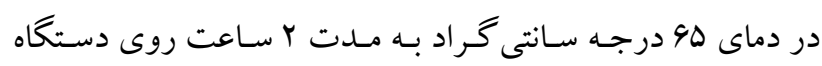

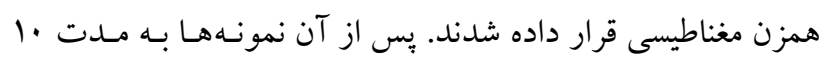

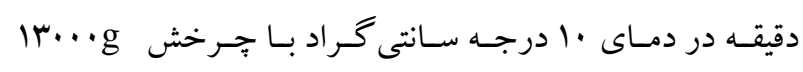

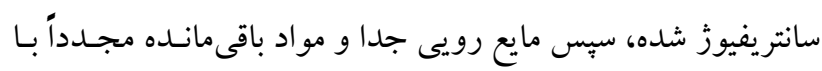
r ميلى ليتر آب مقطر در دماى 90...

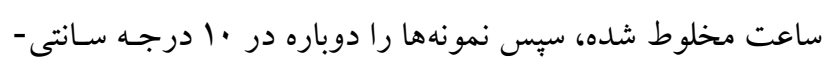

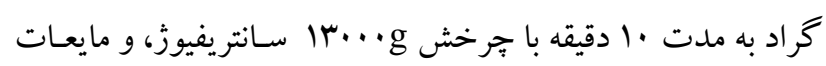

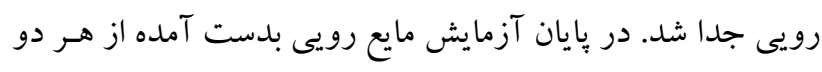

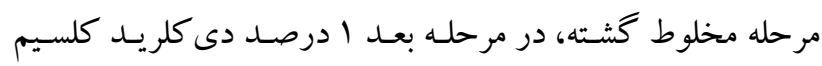
(CaCl 2$)$

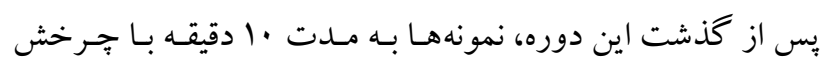

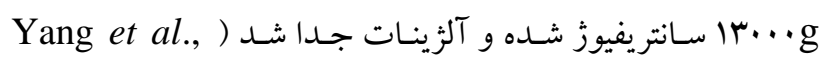
. (2008

\section{تهيه تخم ماهى و تيمار كردن نمونهها} آمادهسازى نمونهها

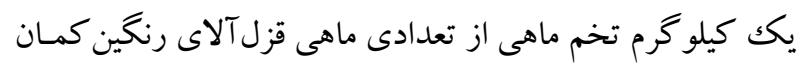

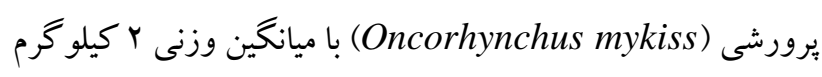
از شـركت قـزل آلا يـرور سـارى واقع در شهرستان سـارى اسـتان

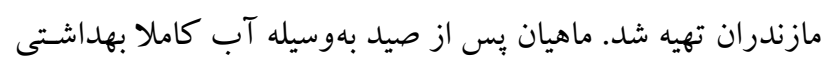

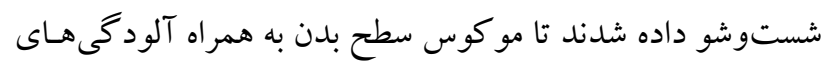

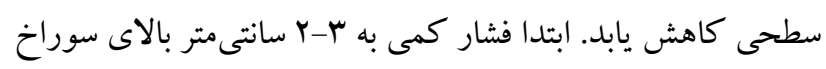

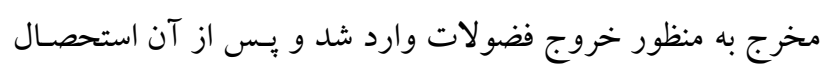

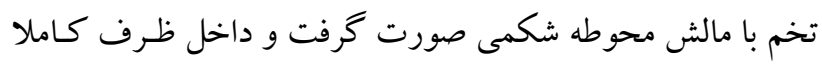

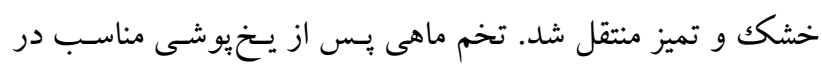

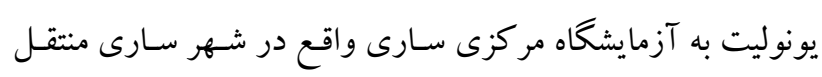

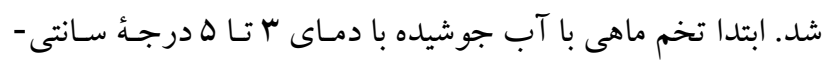
كراد حاوى \%ها انمك خالص (Inanli et al., 2011) به منظور استحكام بيشتر يوسته تخم، خروج لخته هاى خون، الياف بيوندى و

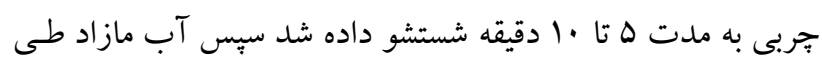

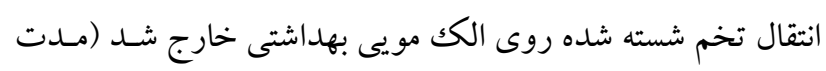

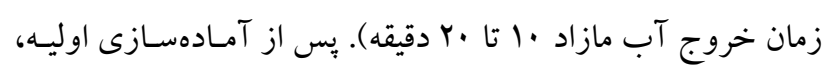

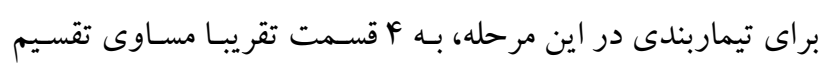

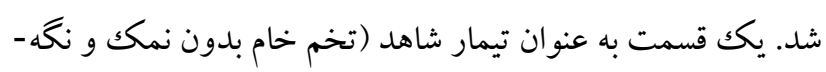

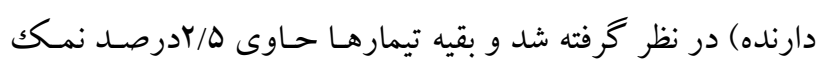


محيط كشت YGC Tكار استفاده شد. بـ از آمادهسـازى و بسـتن

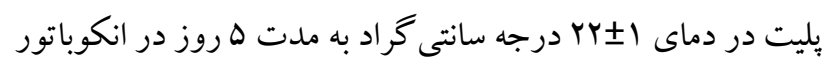
نخهدارى و سبس شمارش انجام شد. تعداد كلنىهاى شمارش شده در عكس رقت اوليه ضرب شده و بر حسب لكاريتم تعـداد كلنى -

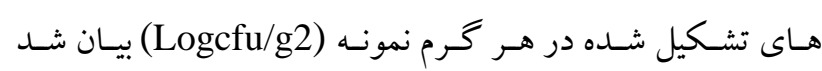

.(Inanli et al., 2011)

ارزيابى حسى اعضاى ثابت ارزياب به تعداد ه نفر انتخاب شدند. نحسوه بررسى آحسى

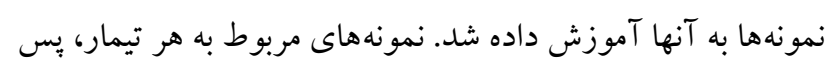

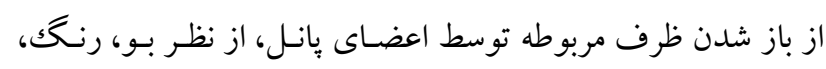

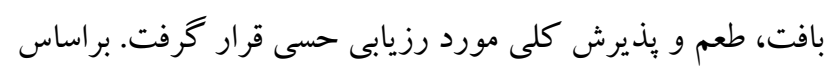

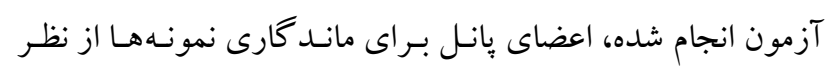
شاخصهاى حسى رنخك، بو، بافت و طعم امتياز دادند. اين امتيازهـا

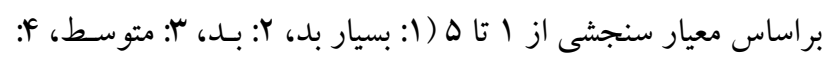
خوب، ه: عالى) در نظر گرفته شده بود (Inanli et al., 2011).

\section{تجزيه و تحليل آمارى}

تجزيه و تحليل آمارى بـا استفاده از نـرمافززار SPSS نسـخه 19

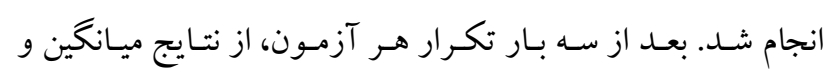
انحراف معيار گرفته شد. براى تجزيه و تحليل دادهها از آزمون جند إند دامنهاى دانكن در سطح احتمال (ه./ • > p)، و براى تحليـل دادهـ هاى حسى از آزمونهاى نايار امترى كروسكال واليس و منويتنىيو

|ستفاده شد.

نتائج

\section{نتايج حاصل از آزمايشات تر كيبات تقريبى}

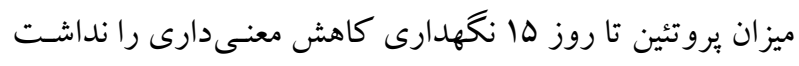

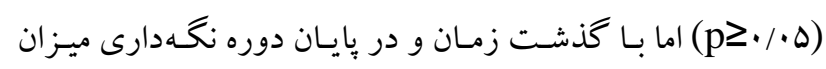

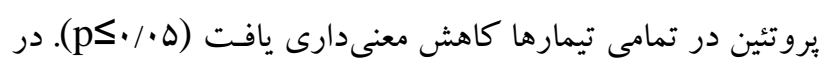

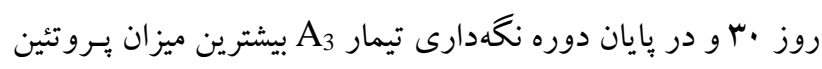
را داشـت كـهـ بـا سـاير تيمارهـا اخـتلاف معنسى دوارى را نشـان داد (ه • • (p). طبق نتايج مقدار جربى، اين فاكتور در تمـامى تيمارهـا

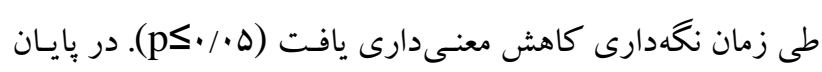

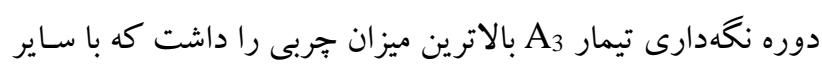
تيمارها اختلاف معنى دارى را نشـان داد (ه •/. (p). در طلى دوره نخهدارى ميزان رطوبت در تمامى تيمارها كاهش معنى دارى يافت

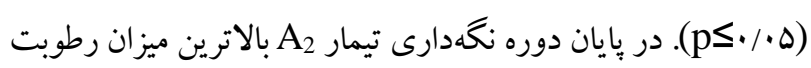

محلول اسيدبوريكك \% r و جند قطره معرق متيل رد بود، جمع شد تا اينكه حجم اسيد بوريكك و بخارهاى ميعـان يافتـه در داخـل آن بـه

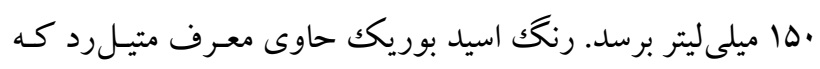
در ابتدا به دليل اسيدى بودن آن قرمز بود، با تجمع بخارهاى حاصل از تقطير به تدريج قليايى شـده و بـه رنــك سـبز در آمـد. در يايـان، محلول حاصل از تجمـع بخارهـاى تقطيـر بـا اسيدسـولفوريكك / /.

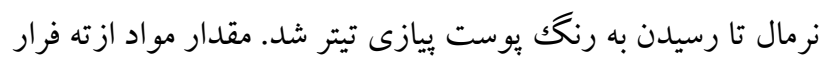

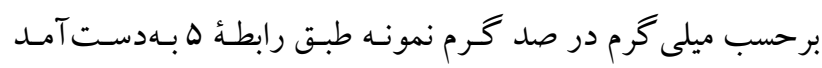

.(Parvaneh, 1998)

حجم مصرفى تيترات = مجموع

بازهاى نيتروزنى فرار (ميلى گرم / . . ا خرم نمونه)

اندازهكيرى شاخص تيوباربيتوريك اسيد (TBA)

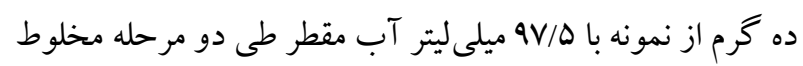

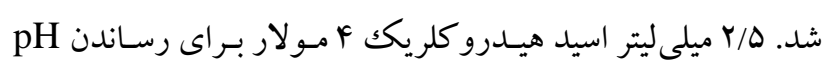

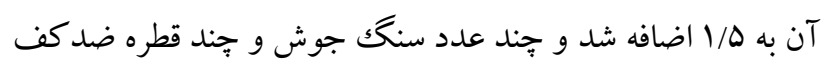

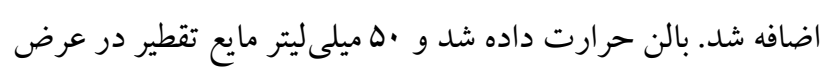
• ا دقيقه از زمان جوش جمع آورى شد. ه ميلى ليتر از مايع تقطير و

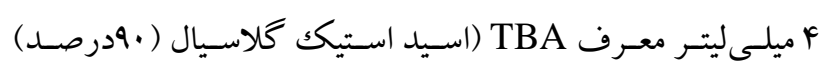

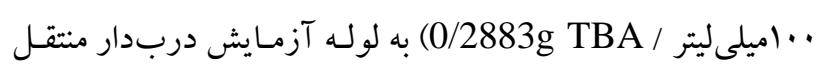

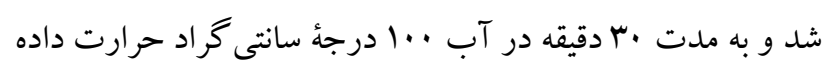

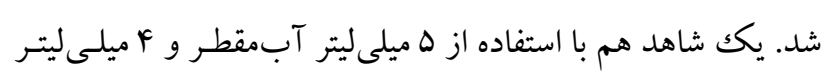
معرف تهيه شد. سيس لوله ها در آب به مدت · لا دقيقه سـرد شـد و

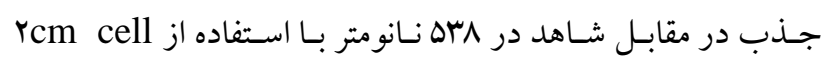
اندازه گيرى شد (Igan et al., 1979).

(مذب خوانده شده) X (ميلى گرم مالوندى آلدهيد در كيلو گرم نمونه)

اندازه كيرى بار ميكروبى براى شـمارش كـل باكترىهـا در نمونسهاى تهيـه شــده، از محيط كشت تريبتيك سويا آكار (TSA) استفاده شـد. بعـد از تهيـه محـيط كشت، توسط ميكروسميلر، / / ميلى ليتر از نمونههاى تهيه شده روى محيط كشت بهطور سطحى يخش شد. در صورت بـالا بـودن تعـداد

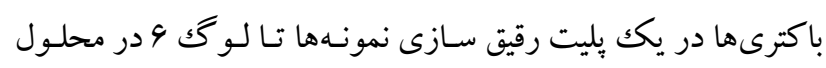

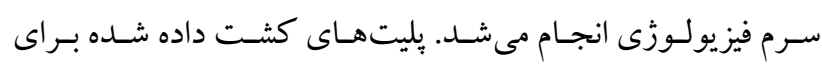

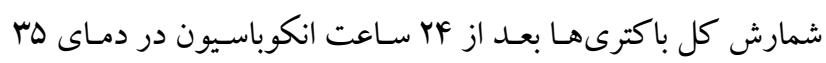
درجهُ سانتى گر اد شمارش شدند (Arashisara et al., 2004). بر اى شمارش كيكك و مخمر آمادهسازى نمونسهــا مشـابه شـمارش

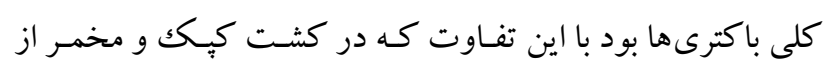




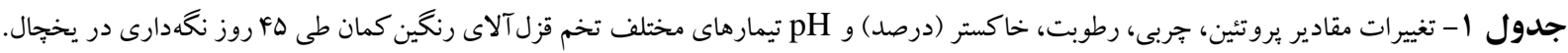

Table 1. Protein, lipid, moisture, ash and pH changes (\%) in different treatments of rainbow trout roe during 45 days of refrigerated storage.

\begin{tabular}{|c|c|c|c|c|}
\hline fo & $r$. & 10 & · & يروتئين / زمان \\
\hline $1 \Lambda / V G \cdot \pm / \mu k C c$ & $r / / 19 \cdot \pm / r)^{B c}$ & $r I / A F \cdot \pm / r / \mu \mathrm{ABb}$ & $r Y / \cdot \pm \cdot \Lambda / 1 \Lambda^{A b}$ & شاهد \\
\hline $\mathrm{r} / / \cdot 4 \cdot \pm / \cdot \mathrm{r}^{\mathrm{Cb}}$ & $r / / \Delta l \cdot \pm / / r^{B b c}$ & $r / / \wedge G \cdot \pm / r r^{\mathrm{ABb}}$ & $r Y / \cdot r \pm \cdot / 19 \mathrm{Ab}$ & $A_{1}$ \\
\hline$r \cdot / ৭ \Delta \cdot \pm / \cdot v^{C b}$ & $r \mid / 9 V \cdot \pm / r l^{B b}$ & $r r / 9 \Lambda \cdot \pm / r r^{\mathrm{Aa}}$ & $r Y / Q r \cdot \pm / Y F^{A a}$ & $\mathrm{~A}_{2}$ \\
\hline $\mathrm{r} / \mathrm{V} 9 \cdot \pm / 19^{\mathrm{Ca}}$ & $r Y / \& G \cdot \pm / \cdot \wedge^{B a}$ & $r r / 91 \cdot \pm / \cdot 1^{\mathrm{Aa}}$ & $r r / \cdot \Lambda \cdot \pm / \Lambda^{\mathrm{Aa}}$ & $\mathrm{A}_{3}$ \\
\hline Fo & $r$. & 10 & $\cdot$ & جربى/ زمان \\
\hline$|r / a r \cdot \pm / 1|^{C b}$ & $\left|r / K^{\prime} G \cdot \pm / r\right|^{B b}$ & $\mid f / \cdot 9 \cdot \pm / \cdot 4^{\mathrm{Aa}}$ & $\mid q / \cdot \pm r \Delta / \cdot q^{\mathrm{Aa}}$ & شاهد \\
\hline $\mid r / / F \cdot \pm / \cdot q^{B b}$ & $\mid r / a \Lambda \cdot \pm / \cdot r^{A a}$ & $|f / r| \cdot \pm / / q^{\mathrm{Aa}}$ & $\cdot / 19 \pm 1 F / r \mathrm{Aa}$ & $A_{1}$ \\
\hline$|r / \cdot r \cdot \pm / /|^{\mathrm{Cb}}$ & $\mid r / A r \cdot \pm / \cdot r \mathrm{Ba}$ & $|f /| \cdots \pm /\left.\right|^{\mathrm{Aa}}$ & $|f /| \Lambda \cdot \pm / \cdot f^{A a}$ & $\mathrm{~A}_{2}$ \\
\hline $1 r / 99 \cdot \pm / \cdot v^{\mathrm{Ba}}$ & $\mid r / a \Lambda \cdot \pm / \cdot r^{\mathrm{Aa}}$ & $\mid F / r \cdot . \pm / \cdot r^{\mathrm{Aa}}$ & $\mid F / r \mu \cdot \pm / 1 q^{\mathrm{Aa}}$ & $\mathrm{A}_{3}$ \\
\hline$F \Delta$ & $\mu$. & 10 & $\cdot$ & رطوبت/زمان \\
\hline$\Delta 9 / \wedge 9 \cdot \pm / \cdot \wedge^{\mathrm{Cc}}$ & $\Delta V / F \wedge \cdot \pm / \mu^{B B c}$ & $\Delta \wedge / 9 \Delta \cdot \pm / r^{A b}$ & $\Delta \Lambda / \cdot \pm 94 / \cdot 9^{\mathrm{Ab}}$ & شاهد \\
\hline$\Delta 9 / \cdot 9 \cdot \pm / \cdot v^{\mathrm{Cd}}$ & $\Delta V / 91 \cdot \pm / r^{B B b c}$ & $\Delta \Lambda / Y r \cdot \pm / \Lambda^{A c}$ & $\cdot / \cdot \mathrm{V} \pm \Delta \Lambda / 1 \varphi^{\mathrm{Ac}}$ & $\mathrm{A}_{1}$ \\
\hline$\Delta \wedge / \wedge q \cdot \pm / \cdot q^{\mathrm{Ca}}$ & $\Delta \Lambda / 9 q \cdot \pm / q \mu \mathrm{BCa}$ & $\Delta q / 1 \Delta \cdot \pm / \cdot q^{\mathrm{ABa}}$ & $\Delta q / r \Delta \cdot \pm / \cdot V^{A a}$ & $\mathrm{~A}_{2}$ \\
\hline$\Delta V / q 1 \cdot \pm / \cdot f^{B b}$ & $\Delta \Lambda / \cdot q \cdot \pm / \cdot 1^{\mathrm{Ab}}$ & $\Delta \Lambda / 19 \cdot \pm / \cdot V^{A c}$ & $\Delta \Lambda / I V \cdot \pm / \cdot \wedge^{A c}$ & $\mathrm{~A}_{3}$ \\
\hline$F \Delta$ & $r$. & 10 & $\cdot$ & خاكستر / زمان \\
\hline$Y / \cdot \Lambda \cdot \pm / \cdot 1^{D d}$ & $r / \cdot q \cdot \pm / \cdot f^{\mathrm{BCd}}$ & $r / \backslash \Delta \cdot \pm / \cdot 1^{A B d}$ & $Y / \cdot \pm 19 / \cdot r^{\operatorname{Ad}}$ & شاهد \\
\hline$r / v \cdot \pm / \cdot 1^{B b}$ & $\Gamma / 9 q \cdot \pm / \cdot 1^{\mathrm{Bb}}$ & $r / q 1 \cdot \pm / \cdot \wedge^{\mathrm{Ab}}$ & $. / .9 \pm r / 94 \mathrm{Ab}$ & $\mathrm{A}_{1}$ \\
\hline$r / f q \cdot \pm / \cdot r^{\mathrm{Bc}}$ & $r / \mathcal{F A} \cdot \pm / \cdot q^{\mathrm{Bc}}$ & $r / \Delta \Lambda \cdot \pm / \cdot r^{\mathrm{ABc}}$ & $r / 9 \Lambda \cdot \pm / \cdot r^{\mathrm{Ac}}$ & $\mathrm{A}_{2}$ \\
\hline $\mathrm{r} / \wedge q . \pm / .1^{\mathrm{Ca}}$ & $r / 99 \cdot \pm / \cdot r^{\mathrm{BCa}}$ & $\kappa / \cdot \Lambda \cdot \pm / \cdot \kappa^{\mathrm{Aa}}$ & $\boldsymbol{r} / \boldsymbol{r} \cdot \pm \pm / \cdot v^{\mathrm{Aa}}$ & $\mathrm{A}_{3}$ \\
\hline$F \Delta$ & $\mu$. & 10 & $\cdot$ & 'زمان/pH \\
\hline$V / F r \cdot \pm / \cdot r^{\mathrm{Aa}}$ & $\mathrm{V} / 19 \cdot \pm / \cdot \mathrm{V}^{\mathrm{Ba}}$ & G/Ar $\pm \pm / 1 \cdot \mathrm{Ca}$ & $9 / \cdot \pm Y V / \cdot r^{\mathrm{Da}}$ & شاهد \\
\hline $\mathrm{V} / \cdot 9 \cdot \pm / \cdot \mathrm{V}^{\mathrm{Aa}}$ & $G / \mu^{A} \cdot \pm / \cdot \kappa^{\mathrm{Bb}}$ & $G / Y r \cdot \pm / \cdot r^{B b}$ & $\cdot / \cdot \mathrm{V} \pm 9 / .9 \mathrm{Cb}$ & $\mathrm{A}_{1}$ \\
\hline$G / \Delta V \cdot \pm / K^{A} \mathrm{Ab}$ & $q / 4 q \cdot \pm / \cdot q^{\mathrm{ABb}}$ & $q / Y V \cdot \pm / \cdot r \mathrm{ABb}$ & $9 / Y \cdot \pm \pm / \cdot 1 \mathrm{Ba}$ & $\mathrm{A}_{2}$ \\
\hline$q / 4 \Delta \cdot \pm / \cdot v^{\mathrm{Ab}}$ & $q / \Gamma \Lambda \cdot \pm / \cdot F^{\mathrm{Ac}}$ & $q / Y \cdot \pm \pm / r 1^{\mathrm{Ab}}$ & $q / 1 V \cdot \pm / \cdot \mu^{\mathrm{Ab}}$ & $\mathrm{A}_{3}$ \\
\hline
\end{tabular}

دادهها به صورت ميانكين سه تكرار I انحر اف معيار بيان شدهاند. (a-c) در هر ستون نشان دهنده تفاوت تيمارها در هر زمان و (A-C) در هر رديف نشان دهنده

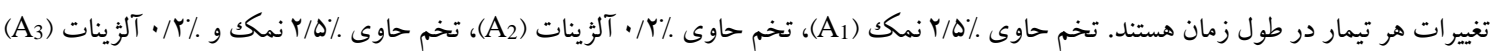

The data are expressed as mean of three replications \pm standard deviation. (a-c) in each column indicates the difference in treatment at any time, and (A-C) in each row represents the variations of each treatment over time. Roe contain $2 / 5 \%$ Salt (A1), roe containing $0.2 \%$ alginate (A2), roe containing $2.5 \%$ salt and $0.2 \%$ alginate (A3).

روز صفر نخهدارى تيمار A2 بيشترين ميزان TVN-B را دارا بـود

كه با ساير تيمارها اختلاف معنى دارى را نشـان داد (ه./. (p). امـا از روز ها تا يايان دوره نگذدارى تيمار شاهد و تيمار A بيشترين و كمترين ميزان TVN-B را داشتند كه با ساير تيمارها اين

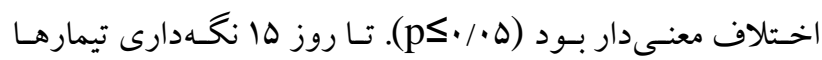

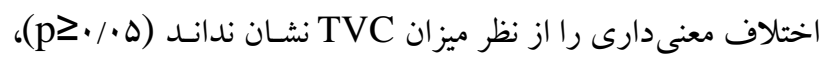
اما از روز ·ط تا يايان دوره نگَدارى بيشترين ميزان TVC را تيمار شاهد دارا بود كـه بـا سـاير تيمارهـا اخـتلاف معنسىدارى را از نظـر

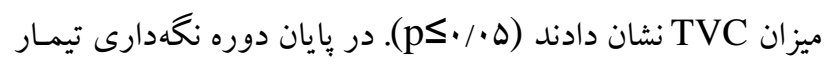
A3 بهترين عملكرد را نشان داد كه با ساير تيمارها اختـلاف معنىى

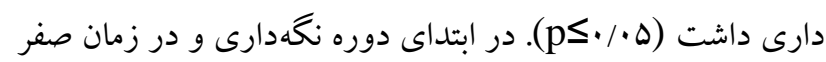

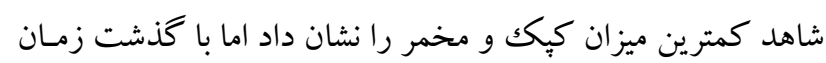

را نشان داد كـه بـا سـاير تيمارهـا اخـتلاف معنـى دارى را نشـان داد

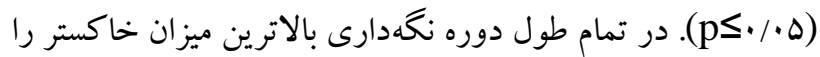
تيمار A3 نشان داد كه با ساير تيمارها اختلاف معنى دارى راداشـت

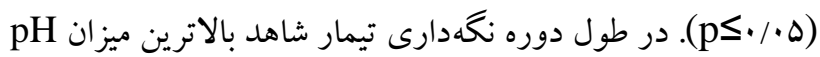
را نشان داد كه در روز صـفر بـا تيمارهـاى A1 و A3، در روز ها و

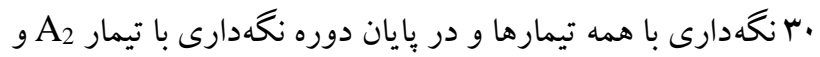

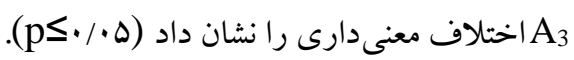

\section{نتايج حاصل از آزمايشات شيميايى و ميكروبى}

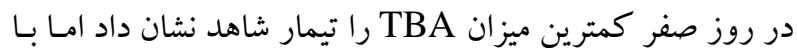
كذشت زمان و از روز ها دوره نگهدارى به بعد در تيمـار شـاهد و تيمار A3 به ترتيب بالاترين و بايينترين ميزان TBA مشـاهده شـد كه با ساير تيمارهـا اخـتلاف معنىىدارى را داشـتند (ه./. (p). در 


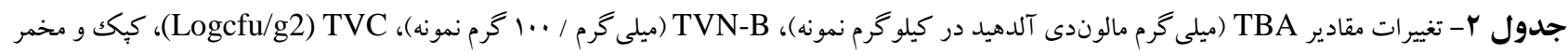

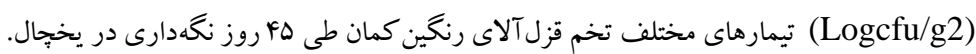

Table 2. TBA (mg malonaldehyde/kg), TVN-B (mg/100g sample), TVC (Logcfu/g2), molds and yeast (Logcfu/g2) changes in different treatments of rainbow trout roe during 45 days of refrigerated storage.

\begin{tabular}{|c|c|c|c|c|}
\hline$F \Delta$ & $r$. & 10 & $\cdot$ & / زمان /TBA \\
\hline$\Lambda / 19 \cdot \pm / \cdot V^{\mathrm{Aa}}$ & $V / 9 \cdot \cdot \pm / \cdot V^{\mathrm{Ba}}$ & $\cdot / 9 \cdot \cdot \pm / \cdot 1^{\mathrm{Ca}}$ & $\cdot / \cdot \pm \Delta \Delta / \cdot \varphi^{\mathrm{Da}}$ & شاهد \\
\hline$F / \cdot \Lambda \cdot \pm / / F^{A b}$ & $1 / v \cdot \pm \pm / \cdot v^{B b}$ & $\cdot / \mathrm{VA} \cdot \pm / \cdot \boldsymbol{F}^{\mathrm{Cab}}$ & $\cdot / \cdot 1 \pm \cdot / 9 \cdot \mathrm{Ca}$ & $A_{1}$ \\
\hline$r / q \cdots \pm / / F^{A b c}$ & $1 / 9 r \cdot \pm / r^{\mathrm{Bb}}$ & $\cdot / A \cdot \cdot \pm / \cdot 1^{\mathrm{Cb}}$ & $\cdot / 9 \mathrm{r} \cdot \pm / .9^{\mathrm{Ca}}$ & $\mathrm{A}_{2}$ \\
\hline$r / V I \cdot \pm / \cdot r A c$ & $|/ r| \cdot \pm / \mid r^{\mathrm{Bc}}$ & $\cdot / V 1 \cdot \pm / \cdot r^{\mathrm{Cc}}$ & $\cdot / 91 \cdot \pm / \cdot r^{\mathrm{Ca}}$ & $\mathrm{A}_{3}$ \\
\hline$F D$ & $\mu$. & 10 & . & \\
\hline$r \cdot / \wedge r \cdot \pm / / r^{\mathrm{Aa}}$ & $r \Delta / 1 \Delta \cdot \pm / \cdot v^{\mathrm{Ba}}$ & $1 \cdot 1 \cdot 9 \cdot \pm / \cdot v^{\mathrm{Ca}}$ & $\Delta / \cdot \pm r \mid / \cdot 1^{D b}$ & شاهد \\
\hline$r Y / F|\cdot \pm / F|^{\mathrm{Ab}}$ & $M / V Y \cdot \pm / V F^{B b}$ & $V / r \mu \cdot \pm / \cdot 1^{C b}$ & $\cdot / \cdot 1 \pm \Delta / 1 \cdot \mathrm{Db}$ & $\mathrm{A}_{1}$ \\
\hline$r / / 91 r \pm / 11^{\mathrm{Ab}}$ & $I V / Y G \cdot \pm / Y \cdot B c$ & $\mathrm{~V} / \mathrm{rq}^{\mathrm{G}} \cdot \pm / \cdot \mathrm{V}^{\mathrm{Cb}}$ & 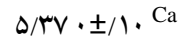 & $\mathrm{A}_{2}$ \\
\hline$r \Delta / / F \cdot \pm / \cdot r^{\mathrm{Ac}}$ & $19 / \cdot 1 \cdot \pm / \cdot 9^{\mathrm{Bd}}$ & $9 / 9 \Lambda \cdot \pm / \cdot k^{\mathrm{Cc}}$ & $\Delta / 19 \cdot \pm / \cdot 1^{D b}$ & $\mathrm{~A}_{3}$ \\
\hline FQ & $r$. & 10 & $\cdot$ & T/ زمان TVC \\
\hline$r / A r \cdot \pm / / r^{\mathrm{Aa}}$ & $r / \mu l \cdot \pm / / \mu^{\mathrm{Ba}}$ & $1 / 4 \cdot \cdot \pm / \cdot 1^{\mathrm{Ca}}$ & $\cdot / \cdot \pm r \cdot / \cdot v^{\mathrm{Da}}$ & شاهد \\
\hline$r / ৭ q \cdot \pm / \cdot v^{A b}$ & $1 / \Delta G \cdot \pm / \cdot \wedge^{\mathrm{Bb}}$ & $\cdot / \wedge 9 \cdot \pm / \cdot 1^{\mathrm{Cb}}$ & $\cdot / \cdot 1 \pm \cdot / 19 \mathrm{Da}$ & $\mathrm{A}_{1}$ \\
\hline$r / \cdot q \cdot \pm / \cdot r^{\mathrm{Ab}}$ & $1 / \mathscr{A} q \cdot \pm / \backslash \Lambda^{\mathrm{Bbc}}$ & $\cdot / A F \cdot \pm / / Y^{C b}$ & $\cdot / \Lambda \cdot \pm /\left.\cdot\right|^{\mathrm{Da}}$ & $\mathrm{A}_{2}$ \\
\hline$r / r r \cdot \pm / l \cdot A c$ & $1 / 19 \cdot \pm / \cdot v^{\mathrm{Bc}}$ & $\cdot / V \cdot \cdot \pm / \cdot v^{C b}$ & $\cdot / r \cdot \pm / \cdot r^{\mathrm{Da}}$ & $\mathrm{A}_{3}$ \\
\hline$F \Delta$ & $r$. & 10 & $\cdot$ & كيكك و مخمر / زمان \\
\hline$r / q \Delta \cdot \pm / \cdot v^{\mathrm{Aa}}$ & $r / 19 \cdot \pm / .9^{\mathrm{Ba}}$ & $\mid / Y 1 \cdot \pm / \cdot k^{\mathrm{Ca}}$ & $. / \cdot \pm 1 \cdot / \cdot 1^{\mathrm{Dc}}$ & شاهد \\
\hline$r / \mu \cdot . \pm / / \mu^{A c}$ & $1 / r q \cdot \pm / \cdot \Delta^{\mathrm{Bb}}$ & $\cdot / \Delta \Lambda \cdot \pm / \cdot \digamma^{\mathrm{Cb}}$ & $\cdot / \cdot r \pm \cdot / \Lambda \wedge^{\mathrm{Da}}$ & $A_{1}$ \\
\hline$r / r r \cdot \pm / 1 \cdot A b$ & $1 / r \cdots \pm / \cdot r^{\mathrm{Bb}}$ & $\cdot / F r \cdot \pm / \cdot 1^{\mathrm{Cc}}$ & $\cdot / 11 \cdot \pm / \cdot 1 \mathrm{Dbc}$ & $\mathrm{A}_{2}$ \\
\hline 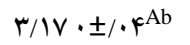 & $\cdot / 99 \cdot \pm / \cdot v^{B c}$ & $\cdot / \mu / \cdot \pm / \cdot \Delta^{\mathrm{Cc}}$ & $\cdot / / F \cdot \pm / \cdot 1^{D b}$ & $\mathrm{~A}_{3}$ \\
\hline
\end{tabular}

دادها به صورت ميانگين سه تكرار 土 انحراف معيار بيان شدهاند. (a-c) در هر ستون نشان دهنده تفاوت تيمارها در هر زمان و (A-D) در هر رديف نشان دهنده

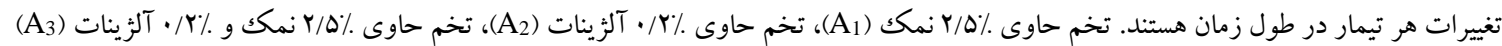

The data are expressed as mean of three replications \pm standard deviation. (a-c) in each column indicates the difference in treatment at any time, and (A-C) in each row represents the variations of each treatment over time. Roe contain $2 / 5 \%$ Salt (A1), roe containing $0.2 \%$ alginate (A2), roe containing $2.5 \%$ salt and $0.2 \%$ alginate (A3).

سرعت فساد يذيرى بالا، اكسيداسيون و تغيير رنخك تخـم مـاهى سبب مى شود تا دوره ماند كارى آن محدود باشـد و بـراى افزايش زمان نخهدارى آن از روش هاى مختلفى استفاده مى شودود در ايسن ميان به استفاده از ضداكسيداسيونهاى طبيعى توجه شده است، لـذا با توجه به مضرات ضداكسيداسيونهاى مصنوعى از جمله سرطانزايى و افزايش آكاهى مردم، امروزه تصور منفى از نخهدارندههـاى شيميايى به موادغذايى در مصرف كنند كان ايجاد شده است. نتايج اندازه گيرى تركيبات تقريبى تيمارهاى مختلف تخم ماهى قزل آلاى رنگين كمان طى مدت نگگهدارى در جدول آ آورده شده است. ميز ان بروتئين تخم خام در گونه هاى متفاوت خـانو اده آزاد ماهيـان

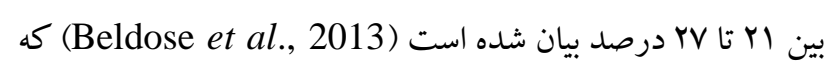
با نتايج اندازه كيرى ميزان يروتئين در مطالعه حاضر نزديـك اسـت.

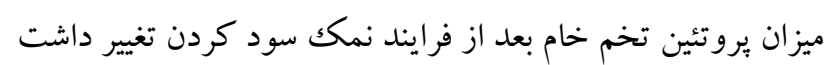

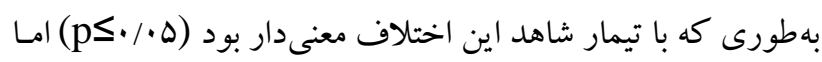

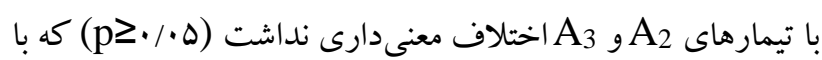

و از روز ها نخهدارى تيمار شاهد بالاترين ميزان اين شاخص را از خود نشان داد كه اين اختلاف با ساير تيمارها معنىدار بود (ه./. (p).

\section{نتايج ارزيابى حسى}

طبق نتايج بهدست آمده شاخص هاى مربوط بـه بافت، بـو، رنك و و يذيرش كلى تمامى تيمارها در طى زمان نگَهدارى كاهش معنىدارى يافت (ه •/p_p)، اين كاهش در تيمار شاهد با سرعت بيشترى اتفـاق افتاد. تا روز ها نخهدارى ميان تيمارها در تمـامى شـاخصهـاى ذكر

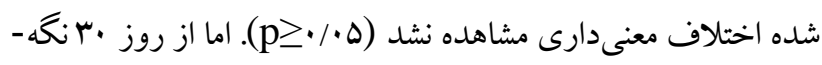
دارى تيمار شاهد بـا سـاير تيمارهـا اخـتلاف معنسىدارى را نشـان داد

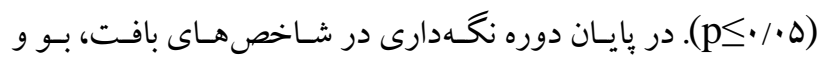

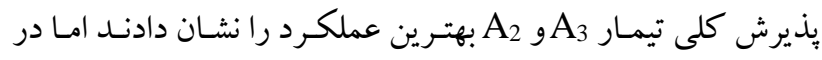
شاخص رنگك فقط تيمار A3 بهترين عملكرد را دارا بود كه بـا سـاير تيمارها اختلاف معنى دارى نشان داد (ه •/p). 


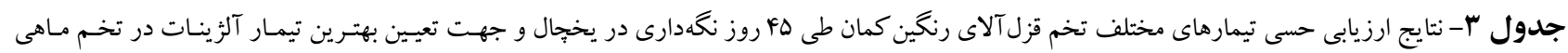
قزل آلاى رنخين كمان.

Table 3. Sensory results of different treatments of rainbow trout roe during 45 days of refrigerated storage and for determination of the best alginate treatment rainbow trout roe.

\begin{tabular}{|c|c|c|c|c|c|}
\hline$F \Delta$ & $r$. & 10 & $\cdot$ & تيمار/زمان & فاكتور \\
\hline$T / T \cdot \cdot \pm / T Y^{C C C}$ & $r / \Lambda \cdot \cdot \pm / T^{\prime B C}$ & $\Delta / \cdots+ \pm / \cdot{ }^{\mathrm{Aa}}$ & $\Delta / \cdots \pm \pm / \cdot{ }^{\mathrm{Aa}}$ & شاهد & \multirow{4}{*}{ بافت } \\
\hline$r / T \cdot \pm \pm / r \digamma^{C b}$ & $f / f \cdot \cdot \pm / r q^{B b}$ & $\Delta / \cdots \pm \pm / \cdot . A$ & $\Delta / \cdots \pm / \cdot{ }^{\mathrm{A} a}$ & $\mathrm{~A}_{1}$ & \\
\hline $\boldsymbol{F} / \Lambda \cdot \pm \pm / \psi^{A A a}$ & $\Delta / \cdots \pm \pm / \cdots A a$ & $\Delta / \cdots \pm \pm / \cdots \mathrm{Aa}$ & $\Delta / \cdots \pm / \cdots{ }^{\mathrm{Aa}}$ & $\mathrm{A}_{2}$ & \\
\hline$\Delta / \cdots \pm \pm / \cdots \mathrm{Aa}$ & $\Delta / \cdots \pm \pm / \cdot{ }^{\mathrm{Aa}}$ & $\Delta / \cdots \pm \pm / \cdots \mathrm{Aa}$ & $\Delta / \cdots \pm / \cdots A$ & $\mathrm{~A}_{3}$ & \\
\hline$r / 9 \cdot \cdot \pm / r Y^{C c}$ & $r / 9 \cdot \cdot \pm / r^{B b}$ & $\Delta / \cdots \cdot \pm / \cdot{ }^{A a}$ & $\Delta / \cdots \pm \pm / \cdot{ }^{A a}$ & شاهد & \multirow{4}{*}{ بو } \\
\hline$r / 9 \cdot \cdot \pm / r f^{C C b}$ & $\boldsymbol{f} / \boldsymbol{f} \cdot \pm \pm / \mu^{\mathrm{Ba}}$ & $\Delta / \cdots \pm \pm / \ldots \mathrm{Aa}$ & $\Delta / \cdots \pm / \cdots A$ & $\mathrm{~A}_{1}$ & \\
\hline$\Gamma / \Lambda \cdot \pm \pm / / \digamma^{\text {Bab }}$ & f/q. • • & $\Delta / \cdots \pm \pm / \ldots$ Aa & $\Delta / \cdots \pm \pm / \cdots$ Аа & $\mathrm{A}_{2}$ & \\
\hline$r / f \cdot . \pm / r f^{\mathrm{Ba}}$ & $\Delta / \cdots \pm \pm / \cdot . \mathrm{Aa}$ & $\Delta / \cdots \pm \pm / \cdots$ Aa & $\Delta / \cdots \pm \pm / \cdots A$ & $\mathrm{~A}_{3}$ & \\
\hline$r / T \cdot \cdot \pm / / Y^{C C c}$ & $r / \mathcal{L} \cdot \cdot \pm / / \mu^{\mathrm{Bc}}$ & $\Delta / \cdots+ \pm / \cdot{ }^{\mathrm{Aa}}$ & $\Delta / \cdots \pm / \cdot{ }^{\mathrm{Aa}}$ & شاهد & \multirow{4}{*}{ رنت } \\
\hline$r / r \cdot \cdot \pm / \cdot \kappa^{\mathrm{Bb}}$ & $\Delta / \cdots \pm \pm / \ldots$ Aa & $\Delta / \ldots \pm / \ldots \mathrm{Aa}$ & $\Delta / \cdots \pm \pm / \cdots$ Aa & $\mathrm{A}_{1}$ & \\
\hline$r / \cdots \pm / r \nabla^{C b}$ & $\boldsymbol{r} / \cdots \cdot \pm / \cdot v^{\mathrm{Bb}}$ & $\Delta / \cdots \pm \pm / \cdots A$ & $\Delta / \cdots \pm / \cdots A$ & $\mathrm{~A}_{2}$ & \\
\hline$r / \Lambda \cdot \cdot \pm / r r^{\mathrm{Ba}}$ & $\Delta / \cdots \pm \pm / \cdots$ Аа & $\Delta / \cdots \pm \pm / \cdots A$ & $\Delta / \cdots \pm / \cdots A$ & $\mathrm{~A}_{3}$ & \\
\hline$T / Y \cdot \cdot \pm / r \omega^{B b}$ & $r / \Lambda \cdot \cdot \pm / T r^{B C}$ & $\Delta / \cdots \pm \pm / \cdot{ }^{A a}$ & $\Delta / \cdots \pm / \cdot{ }^{A a}$ & شاهد & \multirow{4}{*}{ بذيرش كلى } \\
\hline$r / \cdots \pm / r r \mathrm{Ca}$ & $r / \Lambda \cdot \pm \pm / r r^{B a}$ & $\Delta / \cdots \pm \pm / \ldots A a$ & $\Delta / \cdots \pm \pm / \ldots$ Aa & $A_{1}$ & \\
\hline$r / V \cdot \cdot \pm / r r^{C a}$ & $\kappa / \cdots \pm / \mu^{\mathrm{Bb}}$ & $\Delta / \cdots \pm \pm / \cdots A$ & $\Delta / \cdots \pm \pm / \cdots A$ & $\mathrm{~A}_{2}$ & \\
\hline$r / \Lambda \cdot \cdot \pm / / \wedge^{\mathrm{Ba}}$ & 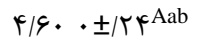 & $\Delta / \cdots \pm \pm / \cdots A$ & $\Delta / \cdots \pm / \cdots A$ & $\mathrm{~A}_{3}$ & \\
\hline
\end{tabular}

دادهها به صورت ميانگين سه تكرار 土ـ انحر اف معيار بيان شدهاند. (a-c) در هر ستون نشاندهندهُ تفاوت تيمارها در هر زمان و (A-D) در هر رديف نشاندهندة تغييرات

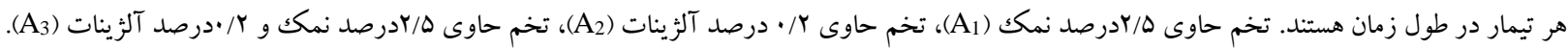

The data are expressed as mean of three replications \pm standard deviation. (a-c) in each column indicates the difference in treatment at any time, and (A-C) in each row represents the variations of each treatment over time. Roe contain $2 / 5 \%$ Salt (A1), roe containing $0.2 \%$ alginate (A2), roe containing $2.5 \%$ salt and $0.2 \%$ alginate (A3).

ميزان جربسى تخـم خـام بعـد از نمـك سـود كـردن تغييـر نيافت و اختلاف معنى

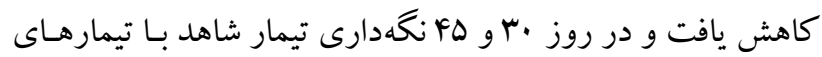
A A $A_{2} A_{1}$ Sengor et al., 2002; Ozpolat et al., ) نتـايج بـا مطالعـات Basby et al., 1998; ) هم خوانى نداشت ولى بـا نتـايج (Inanli et al., 2011 استفاده از درصدهاى متفـاوت نمـك و نخـهدارنــده اسـت. مقـادير جربى مشاهده شده طى مدت نكَهدارى در تمـامى تيمارهـا كـاهش يافت كه ممكن است ناشى از هيدروليز جربى توسط فعاليـتهـاى آنزيمى باشد (Yasemen et al., 2005) اما وجود تر كيب نمـك و نقشى كه آلزينات به عنوان امولسيفاير داشته كـه ذرات روغن را Rioux et al., 2015; Fan ) در آب يخش و نكهدارى مسى كنـد (et al., 2017 در تيمار A3 مانع از تغييرات زياد جربسى در طـول دوره نزخهدارى شد. نتايج مطالعه حاضـر بـا مطالعـات مطابقـت دارد

.(Inanli et al., 2011)
Sengor et al., 2002; Ozpolat \& Patir, 2010; ) مطالعـات مطابقت داشت. ميز ان يـروتئين بـا كذشـت (Inanli et al., 2011 زمان كاهش يافت بهطورى كه اختلاف ميان تيمارها معنىىدار بـود كـه بـا مطالعـات ( Ozpolat \& Patir, 2010; Mirsadeghi et (al., 2015 هـمخـوانى داشـت. ميـزان نمـك فعاليـت آنزيمسى و باكتريايى را تحت تاثير قرار مىدهد همجنين تركيبات آلزينـات از

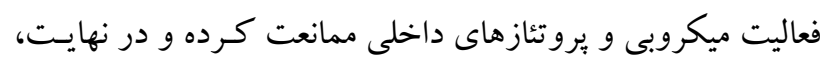
مانع از شكسته شدن يروتئين مى شود كه هرجه ميز ان نكهدارنـدههـا بيشتر باشد فعاليت آنزيمى و باكتريايى كم تـر و در نهايـت كـاهش يـروتئين، كـم تـر اسـت ( Baydar et al., 2004; Luo et al., .(2008; Fan et al., 2009; Al-Enazi \& Naik, 2016 همجنين اختلاف يافته هاى اين تحقيـق بـا سـاير تحقيقـات ناشى از

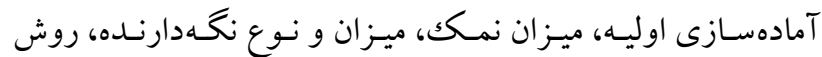
عمل آورى و زمان و شرايط نگهدارى نوع گونه مورد بررسى است. ميزان جربى تخم در خانو اده آزاد ماهيان ^ تا ها درصد بيـان شـده است (Beldose et al., 2013) كـه مشـابه مطالعه حاضـر اسـت. 
جدول ع- نتايج مربوط به اسيدهاى جرب موجود در تخم ماهى قزل آلا طى نگهدارى در يخجال.

Table 4. Fatty acids results in rainbow trout roe during refrigerated storage.

\begin{tabular}{|c|c|c|c|}
\hline \multicolumn{4}{|c|}{ Aيمار A } \\
\hline \multicolumn{4}{|c|}{ دوره نگكدارى(روز) } \\
\hline.$/ 9$. & $\cdot / N 1$ &.$/ \mathrm{V}$ & C14:0 \\
\hline $11 / 11$ & $\mid r / M F$ & $1 \pi / N$. & C16:0 \\
\hline.$/ F Y$ &.$/ \Delta r$ & $\cdot N r$ & C17:0 \\
\hline$r / 91$ & $F / N 1$ & $F / 9 \Delta$ & $\mathrm{C} 18: 0$ \\
\hline$\frac{1}{. / T Y}$ &.$/ A Y$ &.$/ 9$. & C24:0 \\
\hline 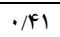 & $\cdot / r$ & - & unknown \\
\hline$r / 1$. & $r / r$. & $r / A$. & C16:1 \\
\hline.$/ 40$ & $\cdot / \wedge \Delta$ & $\cdot / A Y$ & $\mathrm{C} 17: 1$ \\
\hline $19 / 81$ & $r Y / \Delta$. & $r F / 1$. & $\mathrm{C} 18: 1$ \\
\hline $1 / r$. & r/NF & $r / N I$ & $\mathrm{C} 20: \ln 9$ \\
\hline$\cdot / \Delta \mathrm{V}$ & $1 / \Delta \mathrm{V}$ & $1 / N r$ & C24:1n9 \\
\hline $1 / r$. & .190 & .49 & unknown \\
\hline$\Delta / I Y$ & $\Delta / 9 Y$ & 9/90 & C18:2n6 \\
\hline 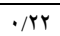 & $\cdot / \mathrm{ND}$ & $\cdot / 1 \mathrm{~A}$ & C18:3n6 \\
\hline.$/ 49$ & .194 &.$/ \Delta \mathrm{V}$ & C18:3n3 \\
\hline.$/ 1$ & $1 / \cdot \cdot$ & $1 / \pi$ & C20:2n6 \\
\hline .109 & $1 / 11$ & $1 / .4$ & C20:3n6 \\
\hline T/VG & $r / \Delta \Lambda$ & $r / q 1$ & $\mathrm{C} 20: 3 \mathrm{n} 3$ \\
\hline r/91 & $r / 19$ & $r / 91$ & C20:5n3 \\
\hline$r .1 .9$ & $r Y / \cdot \cdot$ & $r Y / 1$. & C22:6n3 \\
\hline$\cdot / A$. &.$/ 9$ & $1 / \pi r$ & unknown \\
\hline \multicolumn{4}{|c|}{ تيمار } \\
\hline \multicolumn{4}{|c|}{ دوره نكةدارى(روز) } \\
\hline$\cdot / \Delta r$ & $\cdot / 9$. & $\cdot / \wedge$. & C14:0 \\
\hline $\mid r / M$ & $\mid r / F \Lambda$ & $1 \% / 1 \Lambda$ & C16:0 \\
\hline .194 & $\cdot N \cdot$ & $\cdot / \mathrm{NF}^{\mathrm{F}}$ & C17:0 \\
\hline$r / Y r$ & $F / 11$ & $F / M F$ & C18:0 \\
\hline$\cdot \pi r$ &.$/ 4 T$ &.$/ \Delta \mathrm{A}$ & C24:0 \\
\hline T/FA & $1 / 11$ & $\cdot 1$ & unknown \\
\hline$r / 4$. & $r / \& \Lambda$ & $r / \Delta r$ & C16:1 \\
\hline$\cdot / 4 \Lambda$ & $\cdot / \Delta r$ &.$/ 94$ & $\mathrm{C} 17: 1$ \\
\hline YT/NA & $r \mu / r$. & $r \% / 19$ & $\mathrm{C} 18: 1$ \\
\hline $1 / 90$ & $r / . r$ & $r / 1$. & $\mathrm{C} 20: \ln 9$ \\
\hline $1 / T V$ & $1 / \Delta$ & $1 / \Delta \Delta$ & $\mathrm{C} 24: \ln 9$ \\
\hline $1 / r$. & $\cdot / 1 r$ &.$/ 1 F$ & unknown \\
\hline$\Delta / Q F$ & $9 / 4$. & $9 / 4 \mathrm{~V}$ & $\mathrm{C} 18: 2 \mathrm{n} 6$ \\
\hline .194 & $\cdot / \mathrm{Vq}$ & $\cdot / \mathrm{AF}$ & $\mathrm{C} 18: 3 \mathrm{n} 6$ \\
\hline.$/ 49$ & $\cdot 19$ & $.19 \mathrm{~V}$ & $\mathrm{C} 18: 3 \mathrm{n} 3$ \\
\hline.$/ 9$. & $1 / 10$ & $1 / r$. & $\mathrm{C} 20: 2 \mathrm{n} 6$ \\
\hline$\cdot / \wedge$. & $1 / 1$. & $1 / 1 F$ & $\mathrm{C} 20: 3 \mathrm{n} 6$ \\
\hline$r / 1 F$ & $r / \Delta$. & $r / \Delta \Lambda$ & $\mathrm{C} 20: 3 \mathrm{n} 3$ \\
\hline$r / .1$ & $r / 14$ & $r / r$. & $\mathrm{C} 20: 5 \mathrm{n} 3$ \\
\hline$r \cdot / r \Lambda$ & TI/9. & $r Y / . q$ & C22:6n3 \\
\hline
\end{tabular}

\begin{tabular}{|c|c|c|c|}
\hline \multicolumn{4}{|c|}{ شاهد } \\
\hline \multicolumn{4}{|c|}{ دوره نگهدارى(روز) } \\
\hline r. & 10 & - & اسيد حرب \\
\hline . Ar & $\cdot / 9$ & •/Ar & C14:0 \\
\hline $\mathrm{V} / \Delta \Lambda$ & $1.19 Y$ & $\mid F / Y$. & C16:0 \\
\hline$\cdot \pi r$ & $\cdot / 4 \Delta$ & $\cdot N$ & C17:0 \\
\hline $1 / 10$ & $r / N 1$ & $r / q$. & C18:0 \\
\hline$\cdot / 10$ & $\cdot / 79$ &.$/ 91$ & C24:0 \\
\hline - & • & $\cdot / 1 \Delta$ & Unknown \\
\hline $1 / \cdot 0$ & $r / r \mu$ & r/Ar & C16:1 \\
\hline.$/ 11$ & $\cdot / \mu \Delta$ & $\cdot / \wedge \cdot$ & $\mathrm{C} 17: 1$ \\
\hline $1 . / \cdot r$ & $19 / 14$ & $r F / r$. & C18:1 \\
\hline$\cdot / 4$. & $|/ N|$ & Y $/ \Lambda 1$ & $\mathrm{C} 20: \ln 9$ \\
\hline$\cdot / 4$. & $1 / r$. & $1 / 94$ & $\mathrm{C} 24: \ln 9$ \\
\hline$\cdot / r$ & - & - & unknown \\
\hline$r / v$ & $9 / r r$ & $9 / 9$. & $\mathrm{C} 18: 2 \mathrm{n} 6$ \\
\hline$\cdot / r$. & .19 & $\cdot / \mathrm{AV}$ & $\mathrm{C} 18: 3 \mathrm{n} 6$ \\
\hline$\cdot / r$ & $\cdot / 4 T$ & $\cdot / \Delta 9$ & $\mathrm{C} 18: 3 \mathrm{n} 3$ \\
\hline$\cdot / V^{F}$ & $1 / 19$ & $1 / 49$ & $\mathrm{C} 20: 2 \mathrm{n} 6$ \\
\hline$\cdot / F Y$ & $\cdot / \mathrm{Ar}$ & $1 / \cdot r$ & $\mathrm{C} 20: 3 \mathrm{n} 6$ \\
\hline $1 / 49$ & $r / r Y$ & $r / 91$ & $\mathrm{C} 20: 3 \mathrm{n} 3$ \\
\hline $1 / 1$. & $r / .0$ & $r / r 1$ & $\mathrm{C} 20: 5 \mathrm{n} 3$ \\
\hline $1 \cdot / r \Lambda$ & $1 / 19$. & $r Y / r$. & $\mathrm{C} 22: 6 \mathrm{n} 3$ \\
\hline$\cdot / \Delta r$ & $\cdot / r$ & $\cdot / r r$ & unknown \\
\hline \multicolumn{4}{|c|}{ يمار Ar } \\
\hline \multicolumn{4}{|c|}{ دوره نگهجدارى(روز) } \\
\hline.$/ 9$ & $\cdot / N$ & $\cdot / 91$ & C14:0 \\
\hline $11 / 11$ & $1 \% / 1 F$ & $1 \% / . \Delta$ & C16:0 \\
\hline . $/ F Y$ & $\cdot / \Delta r$ & $\cdot / 4 \Lambda$ & C17:0 \\
\hline$r / 91$ & $F / N 1$ & $F / N \Delta$ & C18:0 \\
\hline$\cdot / \mu Y$ & $\cdot / A Y$ & $\cdot / r$ & C24:0 \\
\hline$\cdot / 41$ & $\cdot / r$ & $\cdot / / r$ & unknown \\
\hline$r / l$. & $r / r$. & $r / 9$. & C16:1 \\
\hline$\cdot / 4 \Delta$ & $\cdot / \wedge \Delta$ & $\cdot / N \Delta$ & $\mathrm{C} 17: 1$ \\
\hline $19 / 01$ & $r Y / \Delta$. & $r \mu / T$ & C18:1 \\
\hline $1 / r$ & $r / / F$ & $r / \mu \Lambda$ & C20:1n9 \\
\hline$\cdot / \Delta \mathrm{V}$ & $1 / \Delta V$ & $1 / 4 V$ & C24:1n9 \\
\hline$r \cdot / 1$ & $\cdot / 90$ & $\cdot \pi$ & unknown \\
\hline$\Delta / I r$ & $\Delta / 9 Y$ & $9 / 9 \mathrm{~V}$ & C18:2n6 \\
\hline$\cdot / Y Y$ & $\cdot / N \Delta$ & $\cdot / v$ & C18:3n6 \\
\hline$\cdot / r q$ & .194 & $\cdot / N^{f}$ & C18:3n3 \\
\hline$\cdot / 1$ & $1 / \cdot \cdot$ & $1 / 19$ & $\mathrm{C} 20: 2 \mathrm{n} 6$ \\
\hline$\cdot / 109$ & $1 / 11$ & $1 / r$. & C20:3n6 \\
\hline T/VG & $r / \Delta \Lambda$ & $r / \Delta 9$ & C20:3n3 \\
\hline$r / 9 \Lambda$ & $r / 19$ & $r / .4$ & C20:5n3 \\
\hline$r .1 .9$ & $r Y / \cdot \cdot$ & $r Y / .9$ & C22:6n3 \\
\hline$\cdot / \wedge$. & $\cdot / 9$. &.$/ .4$ & unknown \\
\hline
\end{tabular}


Inanli et al., 2011; Scano et al., ) مشابه همخوانى نداشت تف 2013; Machado et al., 2016

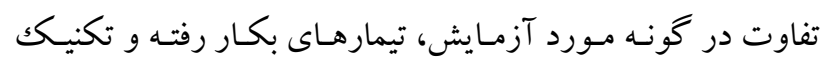

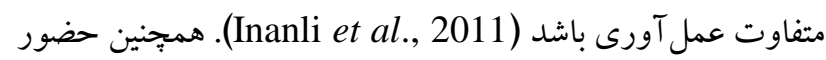
كروههاى ميكروبى در محصول و توليد احتمالى آمينهـاى بيـوزن،

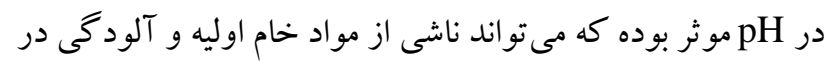

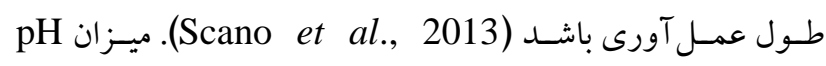

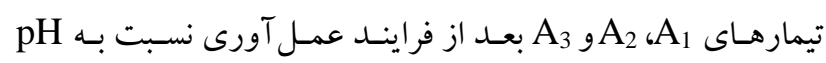
شاهد كاهش يافت كه ناشى از افزودنىهايى مثل نمكك و آلزينـات Fan et al., 2009; Lapa Guimaraes et al., 2011; ) يـا روش عمـل آورى باشـد. مقــدار (Yildiz, 2016 در طـول زمان نكهدارى روندى افزايشى يافت كه اين رونــد در تيمـار شـاهد

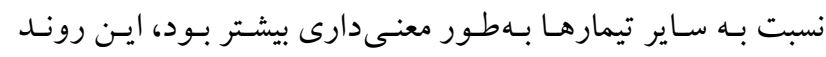

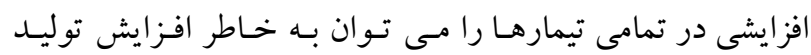

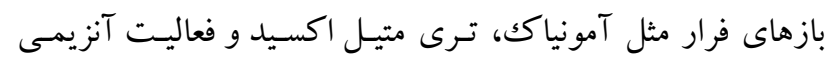

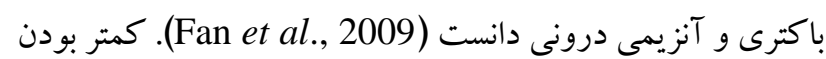

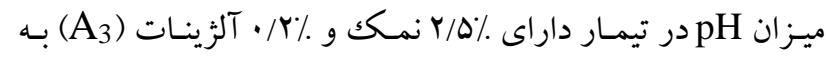
دليل خاصيت ضداكسيداسيونى و ضدباكتريايى آلزينات اسـت بـه-

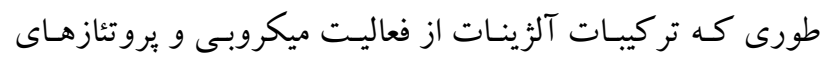

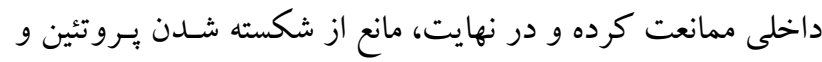

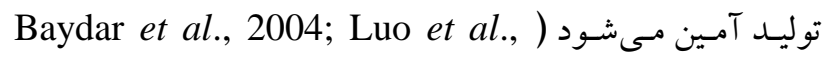

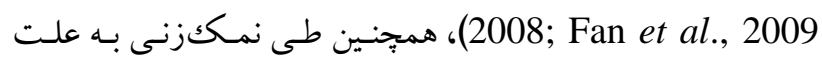

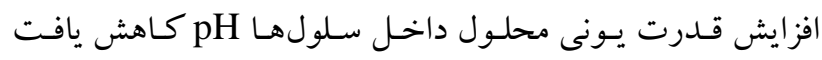

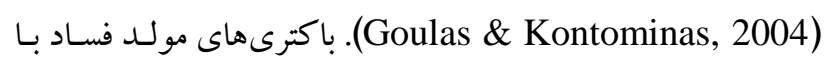

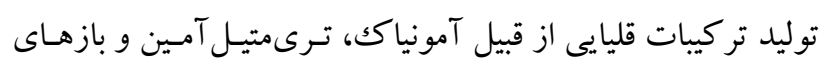

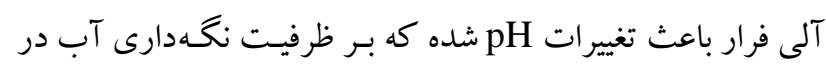

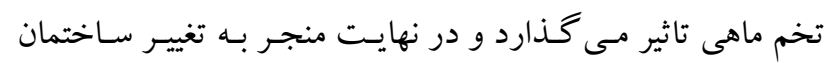

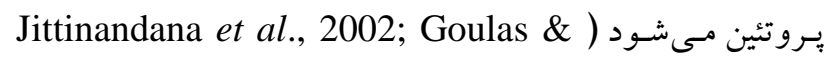
(Kontominas, 2004

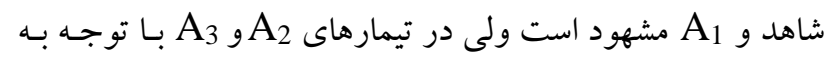

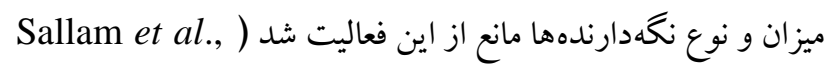

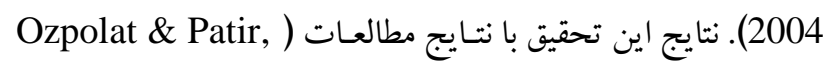

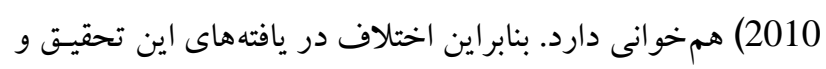

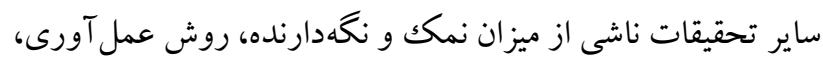
زمان و شرايط نكهدارى و نوع گونه مورد بررسى است.
رطوبت در تيمارهاى مختلف در انتهاى دوره نخــدارى اختـلاف

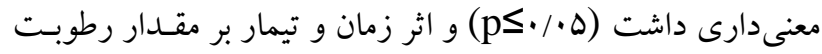

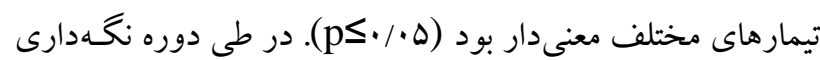
تيمار داراى ٪\%/ • آلزينات (A2) در مقايسه با سـاير تيمارهـا ميزان رطوبت بيشترى نشان داد زير ا يلىسـا كاريدهاى سولفاته توانايى

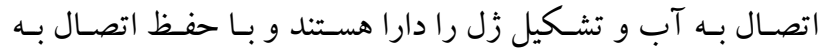

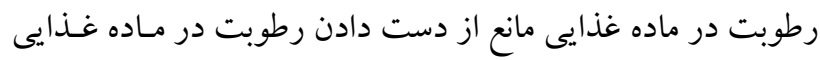
Al-Holy et al., 2005; Arianto \& Bangun, ) مس شود (2016; Gupta et al., 2016; Asadi et al., 2017

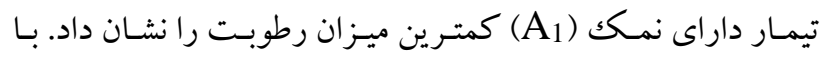

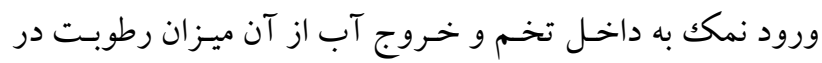

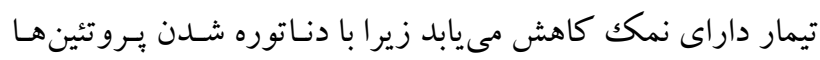

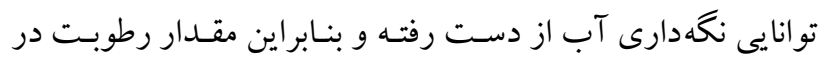
تخم حاوى نمـك كـم مسى شود (Jittinandana et al., 2002).

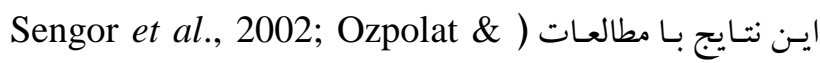
(Patir, 2010; Inanli et al., 2011 تدريجى رطوبت تيمارهاى مورد مطالعه در طول زمان نخهدارى هم

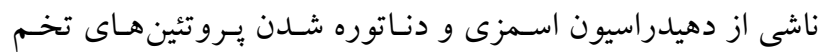

ماهى است (Baydar et al., 2004; Khavari et al., 2016). ميز ان خاكستر تخم ماهى بعـد از عمـل آورى بـهــور معنى دارى

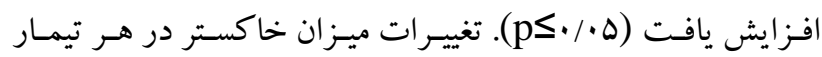

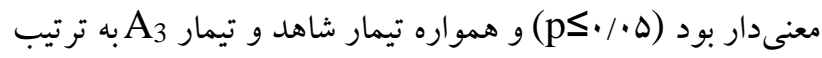

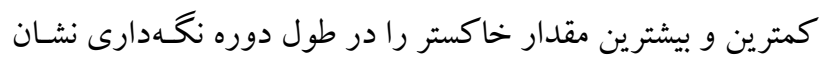

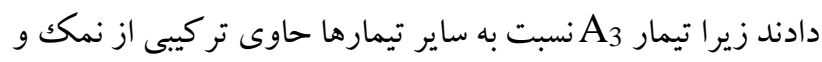

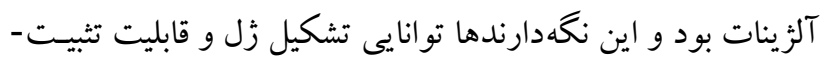

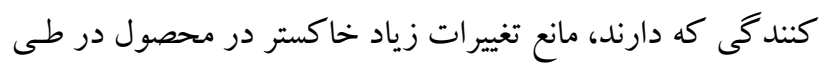

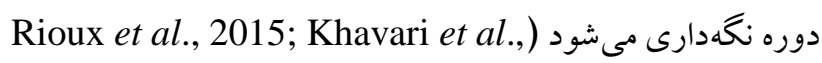

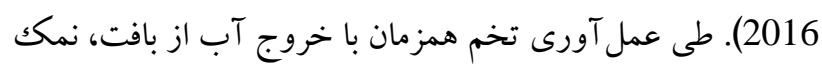

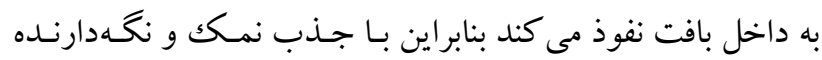
مقدار خاكستر افزايش مى يابـد (Gallart-Jornet et al., 2006).

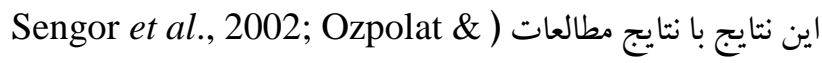
(Patir, 2010; Inanli et al., 2011 بر براى فر آرودههاى شيلاتى مى تواند بهعنوان يكك شاخص فساد

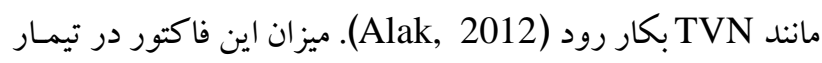

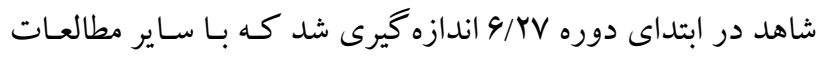


را مى توان دليلى بر اين مورد دانست. مجموع بازهاى نيتروزنى فرار

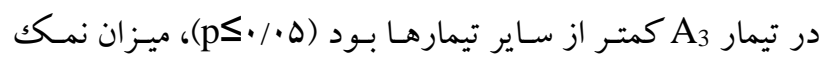

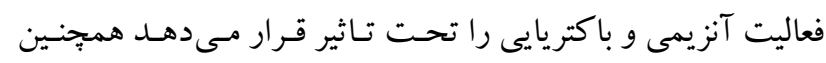

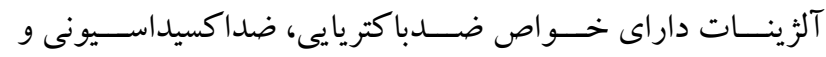
ضدمخمرى است و در كنترل مولكولهاى زيستى فعال نقش دارند Fan et al., 2009; Al-Enazi \& Naik, 2016; Fan et al., ) Ozpolat \& Patir, 2010; ( ) اين نتايج بـا مطالعات (Kirzek et al., 2011

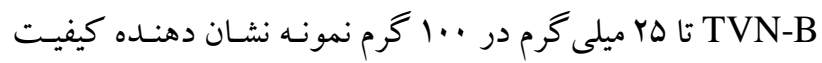

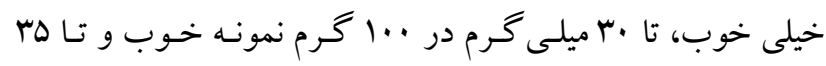

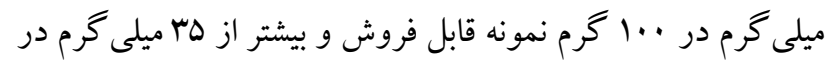

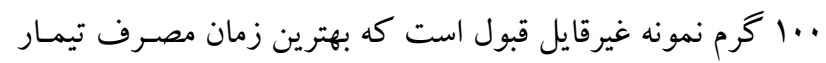
شاهد روز ها، و در بقيه تيمارها روز ·r باست.

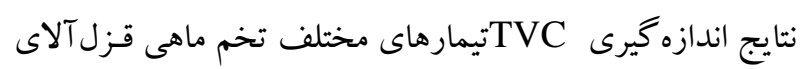

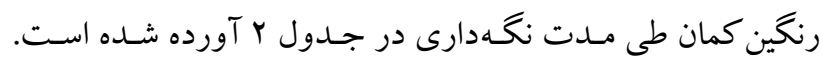
جمعيت بار ميكروبى كل طى زمان نكهدارى در تمامى تيمارها بـه -

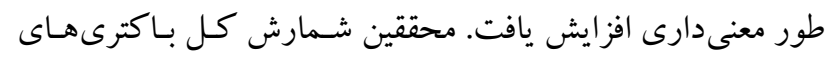
اوليه براى گونههاى مختلف ماهيـان آب شيرين (تيلاوييا، بـاس راه

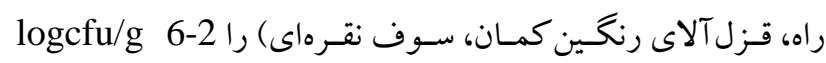
بيشـهاد كردنــ (Etemadi et al., 2008). ميز ان ابتـايى ايـن

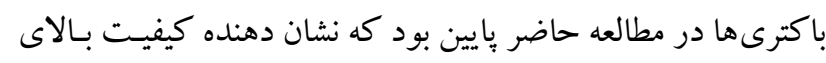

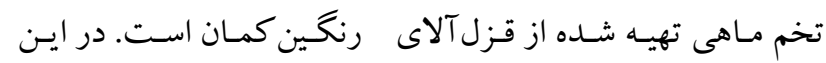
تحقيق تيمار شاهد و تيمار A بيشترين و كمترين جمعيت ميكروبى تهري

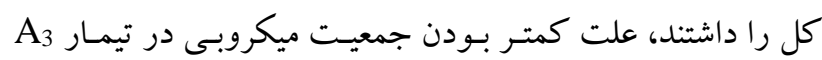

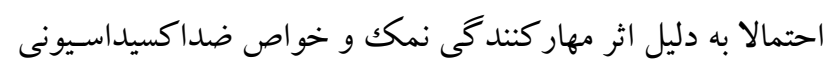

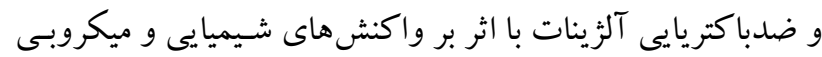

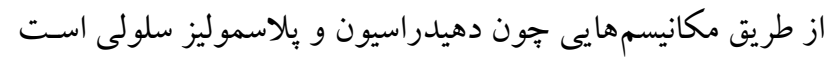
Al-Enazi \& Naik, 2016; Fan et al., 2017; Kim et )

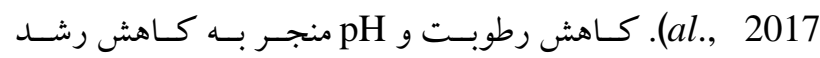

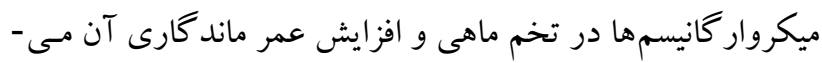

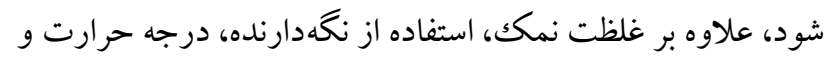
مر احل مختلف عمل آورى تخم نمكك سود ماننــ شستشو و غربـال

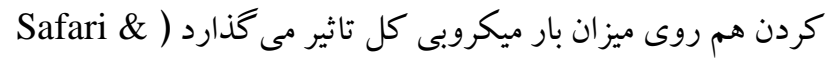

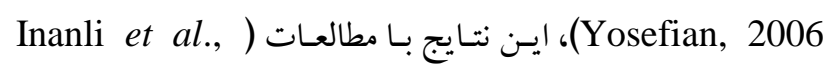
2011) مطابقت دارد.
همانطور كه در جدول Y مشاهده مىشود، ميزان تيوباربيتوريكك

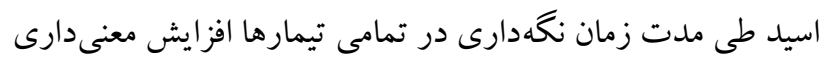

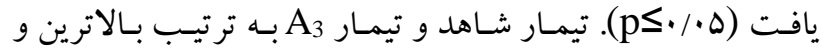
يايين ترين ميزان TBA را نشان داده كـه بـا سـاير تيمارهـا اخـتلاف

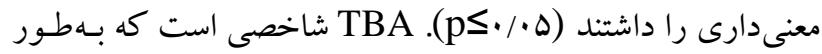

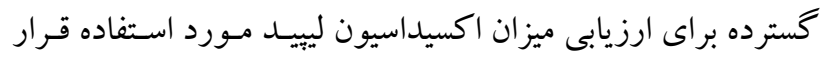
مى گيرد (Yildiz, 2016) و يكى از تغييراتى است كه سبب فسياد محصول مسىشود (Inanli et al., 2011). طـى مر احل ثانويـه

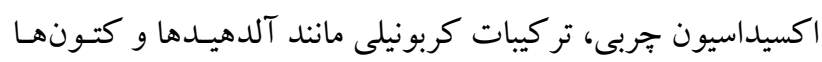

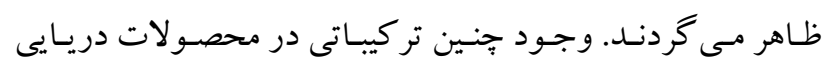

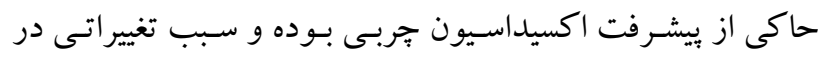

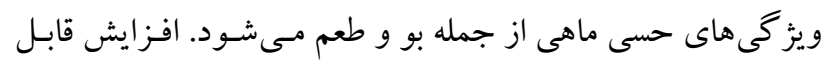

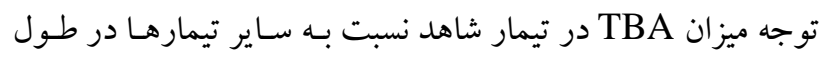

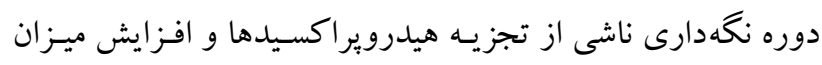

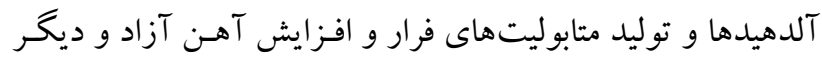

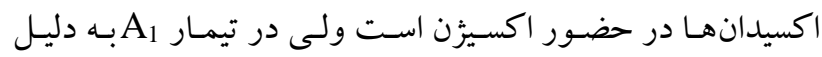

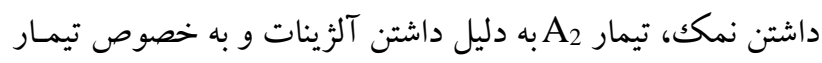

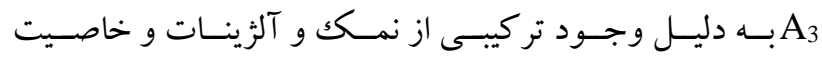
ضداكسيداسيونى و ضـدباكتريايى آلثينـات، مـانع از اكسيداسـيون

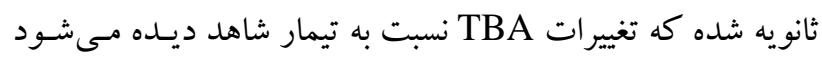
(Al-Enaz \& Naik, 2016; Kim et al., 2017) حاضر با تحقيقات (Inanli et al., 2011) مطابقت دارد. براسـاس نتايج بدست آمده، مقادير TBA تيمار شاهد از روز ·r بنگهدارى و و

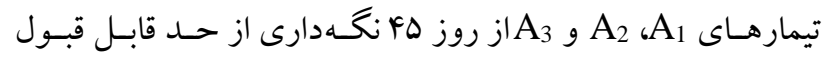
ييشنهادى بيشتر بود. مجموع بازهاى نيتروزنى فرار، شـاخص ميسان

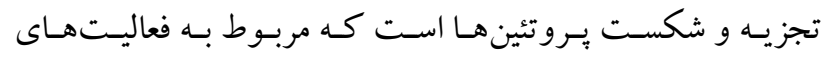

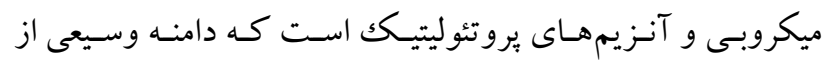

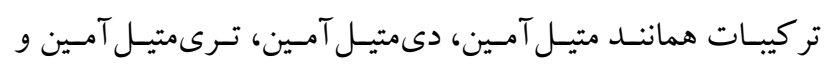

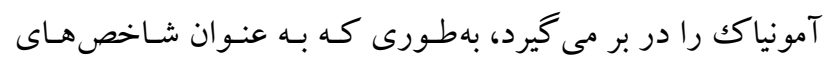

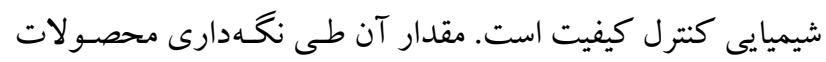

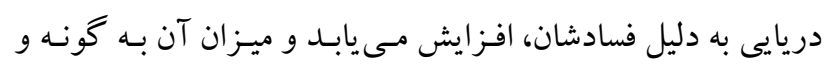

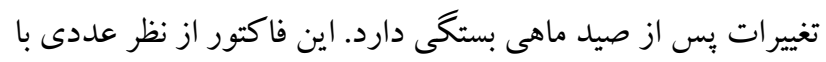

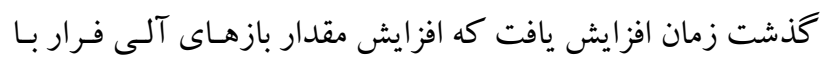

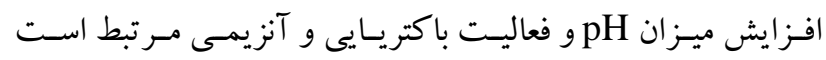
Ailmaz et al., 2009) 


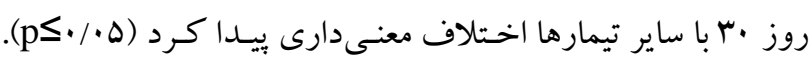

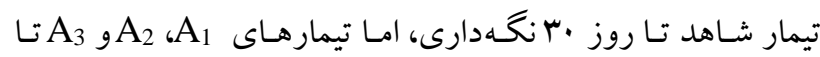
يايان مدت نگهدارى قابل قبول بودند كه بهترين عملكرد را از نظر شاخصهاى بافت، بو و رنكً تيمار A3 از خود نشـان داد. ايسن امـر احتمالا به دليل خواص نكَدارنـدكى خـوب نمـك و آلزينـات در كاهش و يا تاخير فساد ميكروبى و شـيميايى بـه ويـزه اكسيداسـيون ¥ جربى و تيوباربيتوريك اسيد دانست. نتايج مطالعـه حاضـر بـا نتايج (Inanli et al., 2011; Mariutti et al., 2011) كيفيت بافت نمونهها با سرعت كمترى نسبت به رنگك و بو كاهش مى يابد. ابتداى دوره نخَهدارى همـه تيمارهـا داراى بافت محكـم و سفت هستند اما در انتهاى دوره به علت تغيير ماهيـت يسروتئينهـا و كاهش ظرفيت نكَدارى آب از كيفيت بافت كاسته مىشـود. طبتق

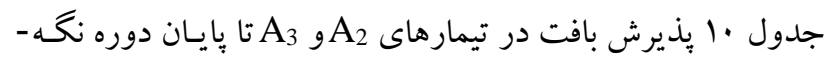
دارى اختلاف معنىدارى مشاهده نشد (ه •/pZ) و در تيمار شـاهد

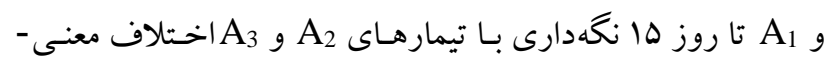
دارى مشاهده نشد (ه •/pZ). همجنين تيمار شاهد از نظر بافت تـا

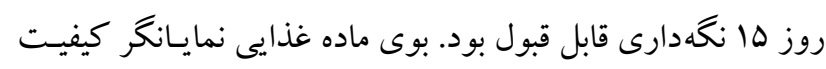

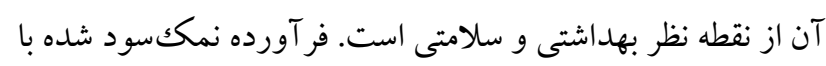
ميز ان نمكك زياد، به دليل اثر نگهدارندگى نمكك بوى مطلوبى دارد.

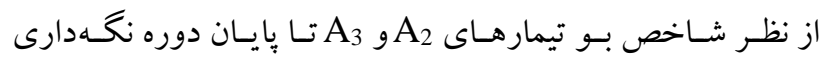
اختلاف معنى دارى را نشان ندادند (ه •/pZ)، تيمار شـاهد تـا روز ها و تيمار A

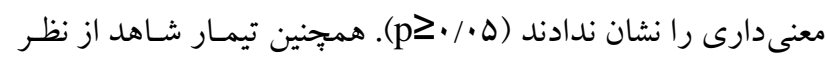

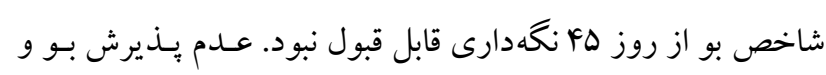
ايجاد بو نامناسب در اواخر دوره نگغدارى در برخى از تيمارها مى تواند ناشى از فعاليت ميكروبى و فساد شيميايى به ويزه اكسيداسيون

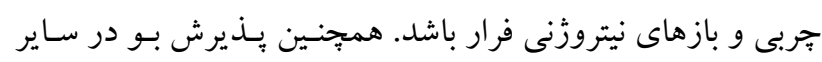

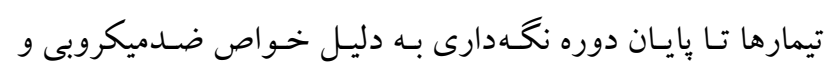
ضداكسيداسيونى نمكك و آلزينات است كه با مطالعـ ( Inanli et مطابقت دارد. در بحث (al., 2011; Mirsadeghi et al., 2015

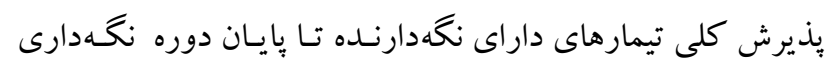

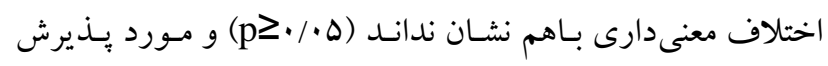

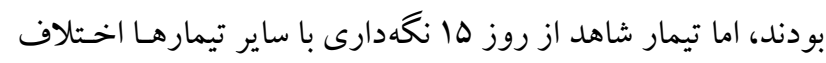

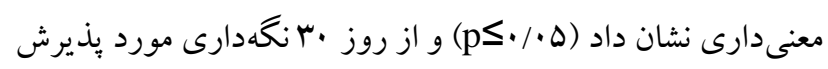

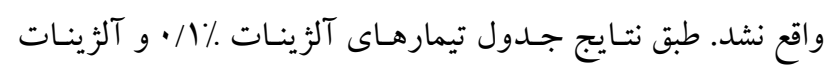

ميـزان كِك و مخمـر طـى زمـان نخـهدارى در تمـامى تيمارهـا افزايش معنى دارى يافتـ. افز ايش ميزان كيُك و مخمـر در تخـم ماهى منجر به تغيير خواص حسى و متعاقباً كاهش كيفيت محصـول

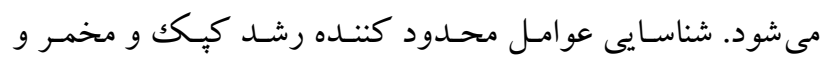
بهينهسازى آن در رابطه با حفظ ايمنى محصول داراى اهميت است

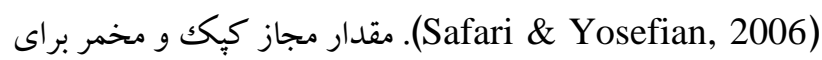

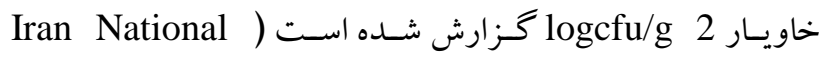
(Standard, 2005 بر اين اساس حد قابل قبـول بيشـنهادى بـراى

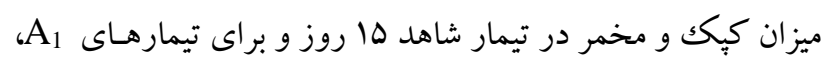

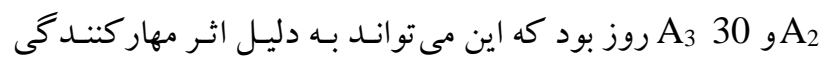
نمكك و خـواص ضداكسيداسـيونى، ضـدباكتريايى، ضـدمخمرى و

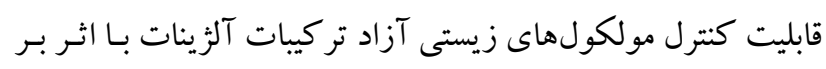
واكـنشهـاى شـيميايى و ميكروبسى از طريـق مكانيسـمهـايى جـون دهيدراسيون و يّاسموليز سلولى، باشد. رعايت بهداشت در مراحل عمل آورى، زمان و شرايط نكـهدارى، توجـه بـه تر كيـب محصـول توليدى مانند غلظت نمكك و ميزان pH و همجيخنين اسـتفاده از مـواد نگهدارنده، تا حدودى آلودكى تخم نمككسود به كيك و مخمر را ماند مى تواند كاهش دهد (Fan et al., 2017; Kim et al., 2017). Etemadi et al., 2005; ) نتايج مطالعـه حاضـر بـا نتـايج مطالعـ (Mirsadeghi et al., 2015 نتايج ارزيابى حسى در جـدول ب نشـان داده شـده اسـت. رنـكَ نقش مهمى در ارزيابى كيفى محصسول دارد. يـذيرش محصسولات

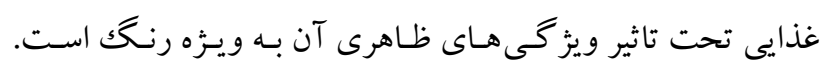

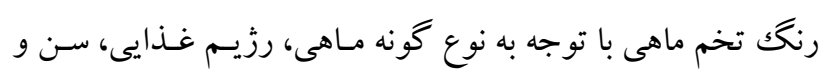
مرحله بلوغ متفاوت است (Beldose et al., 2003). رنـك تخـم آزاد ماهيان از نارنجى روشن تا نارنجى تيره و قرمـز تغييـر مسى كنــ Majazi Amiri \& Rezaei Tavabe, 2010) كارو تنوئيدى به شرايط عمل آورى مانند گرما و اكسيداسيون بسيار

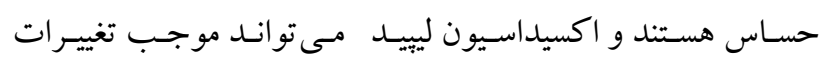
شيميايى و كاهش غلظت كارتنوئيدها و در نهايت منجر بـه رنـكـبرى تخم نمككسـود شـود (Birkeland et al., 2004). رطوبـت هم با ايجاد شاخص هاى انكسارى در ماتريكس مواد غـذايى منجـر

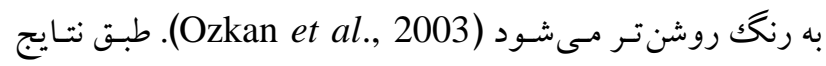
بدست آمده در جدول ·1 رنخك در تيمارهـاى مختلف تـا روز 10

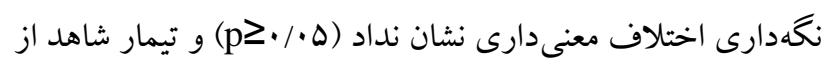


توانايى تشكيل زل، خاصيت امولسيفايرى، قابليت تثبيت كنندگى و

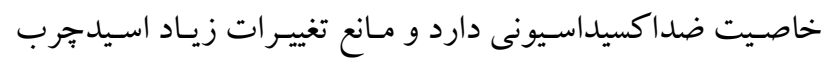

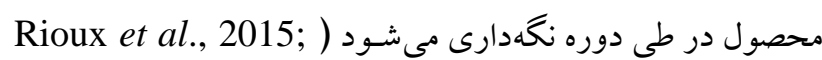

.(Khavari et al., 2016

\section{نتيجها كيرى}

نتايج تجزيه و تحليل هـاى شيميايى نشـان داد كـه بـه طور كلى

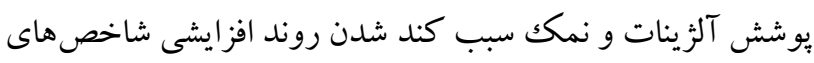
فساد اكسيداسيونى نسبت به تيمار شاهد شد. در انتهاى دوره تيمار

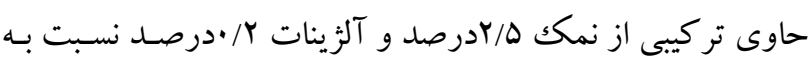

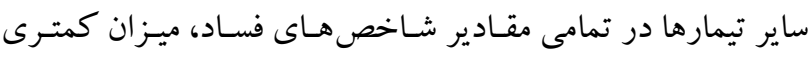

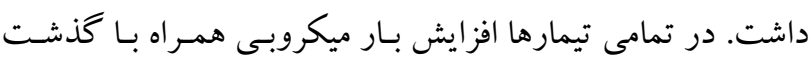

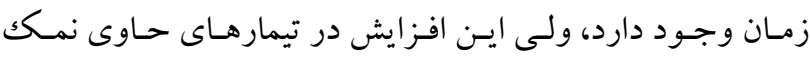

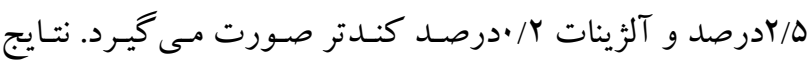
ارزيـابى حسى نيـز بيـانكر ايـن مطلـب اسـت كـهـ تيمـار آلزينـات

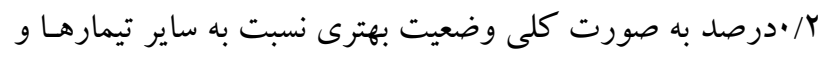

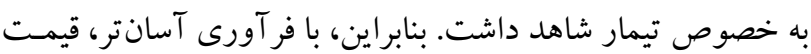
بايين تر و در دسترس بودن مواد و وسايل مـورد نياز جهـت عمـل -

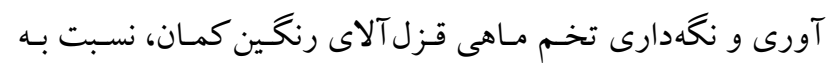

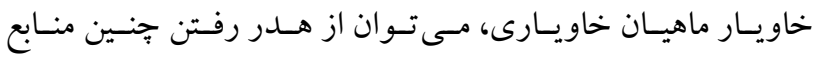

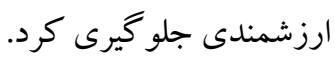

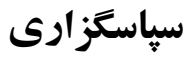

بدينوسيله از حمايت مالى دانشخاه علوم كشاورزى و منابع طبيعى دئ كر گان در انجام يزوهش قدردانى مى گردد.

\section{REFERENCES}

Alak, G. 2012. Effect of chitosan prepared in different solvents on quality parameters of mackerel fillets. Asian J. Ani. Vet. Adv. 11: 2813-2816.

Al-Enazi, T.A. and Naik, A.V. 2016. Disinfection of alginate and addition silicon rubber-based impression materials. - Inter J. Stoma. Occlu. Med. 8: 44-48.

Al-Holy, M., Wang, Y., Tang, J. and Rasco, B. 2005. Dielectric properties of salmon (Oncorhynchus keta) and sturgeon (Acipenser transmontanus) caviar at radio frequency (RF) and microwave (MW) pasteurization frequencies. - J. Food Engin. 70: 564-570.

Arashisara, Ş., Hisara, O., Kaya, M. and Yanik, T. 2004. Effects of modified atmosphere and vacuum packaging on microbiological and chemical properties of rainbow trout (Oncorynchus mykiss) fillets. - Inter J. Food Microb. 97: 209-214.

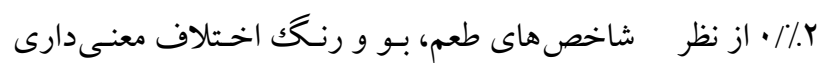

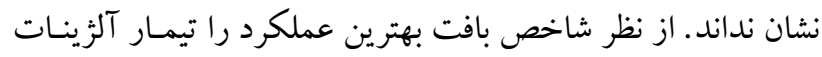

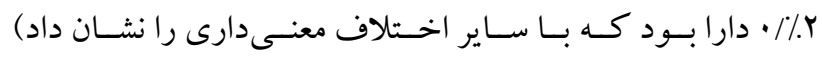

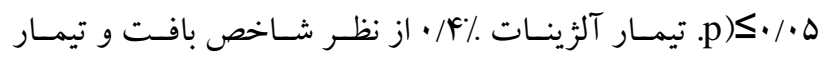

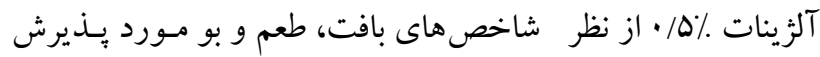

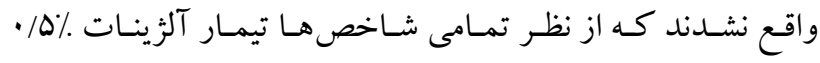

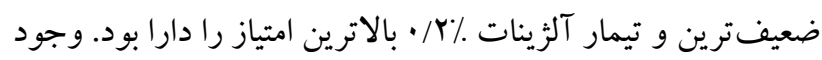

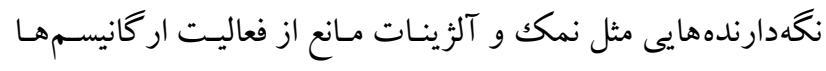

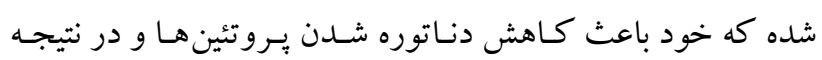

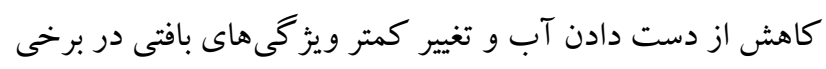

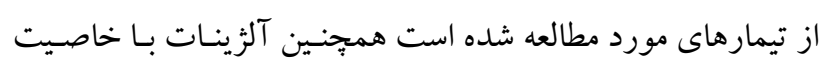

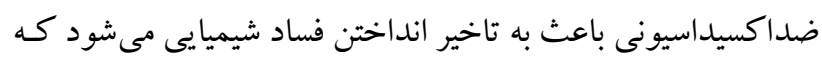

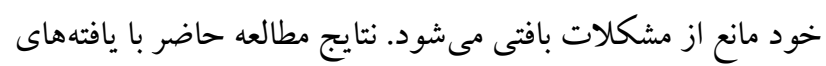
Sallam et al., 2004; Inanli et al., 2011; Mirsadeghi ) (et al., 2015; Asadi et al., 2017 طبق جدول F مقادير اسيدهاى جرب اشباع و غير اشباع در تمـامى

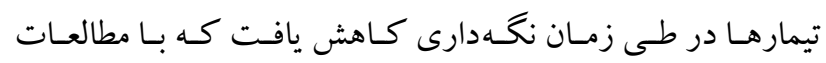
هirsadeghi et al., 2015) مغايرت داشت كـه مى توانــ بـهدليـل (Mariutti et al., 2011)

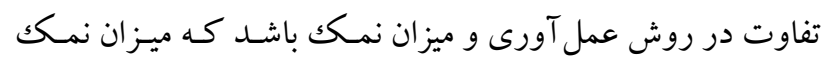

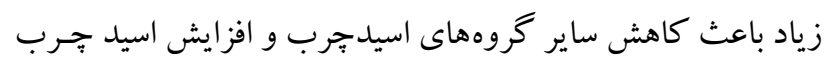

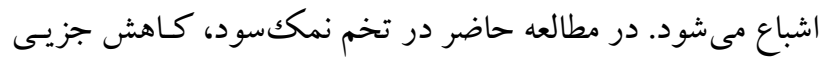

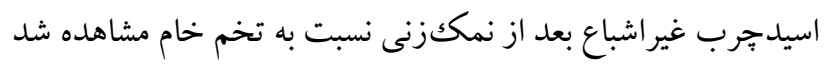

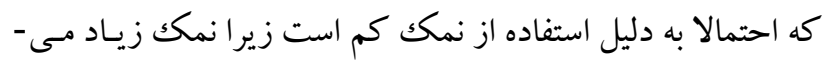

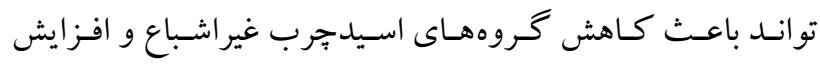
Mariutti et ( اسيدجرب اشباع شود. نتايج مطالعه حاضر با مطالعه (al., 2011; Mirsadeghi et al., 2015

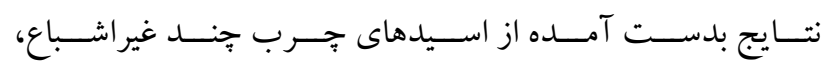

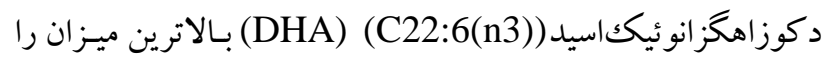

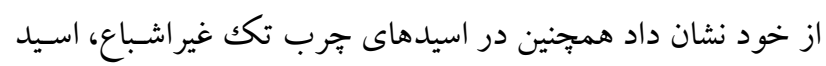

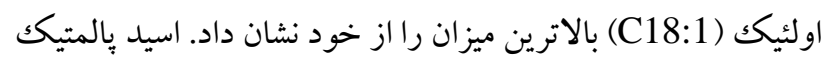

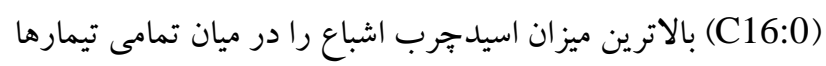

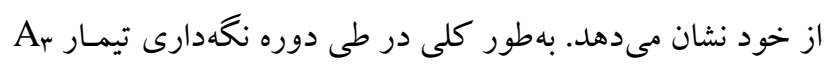

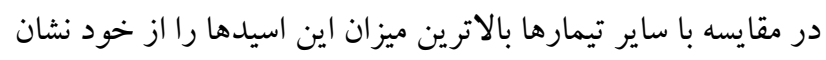

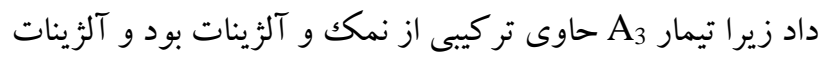


Arianto, A. and Bangun, H. 2016. Healing effect of alginate liquid against $\mathrm{HCl}$-induced gastric mucosal lesions in rats. - Inter J. Pharm.Tech. Res. 9: 287-296.

Asadi Farsani, O., Kordjazi, M., Shabanpour, B., Ojagh, S.M. and Jamshidi, A. 2017. Effect of antioxidant properties of brown algae (Iyengaria Stellata) extract on the shelf-life and sensory properties of rainbow trout (Oncorhynchus mykiss) fillet nugget during frozen storage. - Master's thesis. $80 \mathrm{p}$.

Basby, M., Jappesen, V.F. and Huss, H.H. 1998. Spoilage of lightly salted Lumpfish (Cyclopterus lumpus) roe at $5{ }^{\circ}$ C. - J. Aqua. Food Pro. Tech. 7: 23-34.

Baydar, N.G., Ozkan, G. and Sagdic, O. 2004. Total phenolic contents and antibacterial activities of grape (Vitis vinifera) extracts. - J. Food Con. 15: 335-339.

Benjakul, S., Intarasirisawat, R. and Visessanguan, W. 2011. Chemical compositions of the roes from skipjack, tongol and bonito. - J. Food Chem. 124: 1328-1334.

Birkeland, S., Haarstad, I. and Bjerkeng, B. 2004. Effects of salt curing procedure and smoking temperature on astaxanthin stability in smoked salmon. - J. Food Sci. 69: 198-203.

Bledsoe, G.E., Bledsoe, C.D. and Rasco, B. 2003. Caviar and fish roe products. - J. Criti. Rev. Food Sci. Nut. 43: 317-356.

Etemadi, H., Rezaei, M. and Abedian, A. 2008. Antioxidant and anti-bacterial potential of Rosmarinus officinalis extract in increasing the shelf life of rainbow trout(Oncorhynchus mykiss). - J. Food Sci. Tech. 5: 67-77.

Fan, W., Sun, J., Chen, Y., Qiu, J., Zhang, Y. and Chi, Y. 2009. Effects of chitosan coating on quality and shelflife of silver carp (Hypophthalmichthys molitrix) during frozen storage. - J. Food Chem. 115: 66-70.

Fan, Y., Wu, Y., Fang, P. and Ming, Z. 2017. Facile and effective synthesis of adsorbent-utilization of yeast cells immobilized in sodium alginate beads for the adsorption of phosphorus in aqueous solution. - Wat. Sci. Tech. 75: 75-83.

Gallart-Jornet, L., Barat, J.M., Rustad, T., Erikson, U., Escriche, I. and Fito, P. 2006. Influence of brine concentration on Atlantic salmon fillet salting. - J. Food Engin. 80: 267-275.

Goulas, A.E. and Kontominas, M.G. 2004. Effect of salting and smoking method on the keepin quality of chub mackerel (Scomber japonicus) biochemical and sensory attributes. - J. Food Chem. 93: 511-520.

Gupta, P., Adhikary, M., Christakiran, J.M., Kumar, M., Bhardwaj, N. and Mandal, B.B. 2016. Biomimetic, osteoconductive non-mulberry silk fiber reinforced tricomposite, scaffolds for bone tissue engineering. ACS. Appl. Mat. Inter. 8: 30797-30810.

Igan, J.O., King, J.A., Pearson, A.M. and Gray, I.I. 1979. Influence of hemepigments, nitric and non-heme iron on development of warmed-over flavore (WOF) in cooked meat. - J. Agri. Food. 27: 830-842.

Inanli, A., Oksuztepe, G., Ozpolat, E. and Coban, O. 2011. Effect of acetic acid and different salt concentrations on the shelf life of caviar from Rainbow trout (Oncorhynchus mykiss). - J. Ani. Vet. Adv. 10: 3172-3178.
National Iranian Standard, 2005. Caviar - Specifications and test methods. 186, $27 \mathrm{p}$.

Jittinandana, S., Kenney, P.B., Slider, S.D. and Kiser, R.A. 2002. Effect of brine concentration and brining time on quality of smoked rainbow trout fillets. - J. Food Sci. 67: 2095-2099.

Khavari, A., Nyden, M., Weitz, D.A. and Ehrlicher, A.J. 2016. Composite alginate gels for tunable cellular microenvironment mechanics. - Sci. Rep. 6: 1-10.

Kim, J.H., Park, S., Kim, H., Kim, H.J., Yang, Y.H. and Kim, Y.H. 2017. Alginate/bacterial cellulose nanocomposite beads prepared using gluconacetobacter xylinus and their application in lipase immobilization. - Carbohydr. Polymer. 157: 137-145.

Kirzek, M., Vacha, F. and Pelikanova, T. 2011. Biogenic amines in carp roe (Cyprinus carpio) preserved by four different methods. - J. Food Chem. 126: 14931497.

Lapa Guimaraes, G., Trattner, S. and Pickova, J. 2011. Effect of processing on amine formation and the lipid profile of cod (Gadus morhua) roe. - J. Food Chem. 129: 716-723.

Luo, Y., Shen, H., Pan, D. and Bu, G. 2008. Gel properties of surimi from silver carp (Hypophthalmichthys molitrix) as affected by heat treatment soyporosolate. - J. Food hydrocoll. 22: 1513-1519.

Machado, T.M., Tabato, Y.A., Takahashi, N.S., Casarini, L.M., Neiva, C.R.P. and Henriques, M.B. 2016. Caviar substitute produced from roes of rainbow trout (Oncorgynchus mykiss). - Acta. Scie. Tech. 2: 233240.

Majazi Amiri, B. and Rezaei Tavabe, K. 2010. In the translation of sturgeon and caviar. -Tehran University Press, 256 pp.

Mancini, F. and McHugh, T.H. 2000. Fruit-alginate interactions in novel restructured products. - Nahrung 44: 152-157.

Mariutti, L.R.B., Orlien, V., Bragagnolo, N. and Skibsted, L.H. 2011. Effect of sage and garlic on lipid oxidation in high-pressure processed chicken meat. J. Food Res. Tech. 227: 337-344.

Meillisa, A., Woob, H.C. and Chun, B.S. 2015. Production of monosaccharidesand bio-active compounds derived from marine polysaccharides usingsubcritical water hydrolysis. - J. Food Chem. 171: 70-77.

Mirsadeghi, H., Alishahi, A.R., Shabanpour, B. and Safari, R. 2015. Fatty acid composition and qualitative changes of salted rainbow trout (Oncorhynchus mykiss) roe during refrigerator storage. - Per. Sea. Sci. Tech. 1: 21-29.

Mirsadeghi, H., Alishahi, A.R., Shabanpour, B. and Safari, R. 2015. Effect of salt and water temperature on the qualitative changes of Oncorhynchus mykiss roe in refrigerated storage. - J. Fisher. Sci. Tech. 4: 93-104.

Ozkan, M., Kirca, A. and Cemeroglu, B. 2003. Effect of moisture content on CIE color values in dried apricots. - J. Europ. Food Res. Tech. 216: 217-219. 
Ozpolat, E. and Patir, B. 2010. Changes in sensorial and chemical quality vacuumed of rainbow trout (Oncorhynchus mykiss) when producing caviars and storageing. - J. New World Sci. Acad. 5: 336-343.

Parvaneh, V. 1998. Quality control and chemical testing of food. - Tehran University Press, 332 p.

Rioux, L.E. and Turgeon, S.L. 2015. Seaweed carbohydrates. - In: tiwari, B.K., Troy, D. (Eds.), seaweed sustainability. Elsevier, San Diego. 141-192 pp.

Safari, R. and Yosefian, M. 2006. Changes in TVN (Total Volatile Nitrogen) and psycrotrophic bacteria in Persian sturgeon Caviar (Acipenser persicus) during processing and cold storage. - J. Appl. Ichthy. 22: 416-418.

Sakthivel, R. and Pandima D.K. 2015. Evaluation of physicochemical properties, proximate and nutritional composition of Gracilaria edulis collected from Palk Bay. - J. Food Chem. 174: 68-74.

Sallam, K.I., Ishioroshi, M. and Samejima, K. 2004. Antioxidant and antimicrobial effects of garlic in chicken sausage. - J. Food Sci. Tech. 37: 849-55.

Scano, P., Rosa, A., Pisano, M.B., Piras, C., Cosentino, S. and Dessi, M.A. 2013. Lipid components and water soluble metabolites in salted and dried tuna (Thunnus thynnus L.) roes. - Food Chem. 138: 2115-2121.

Sellimia, S., Younes, I., Ayed, H.B., Maalej, H., Montero, V., Rinaudo, M., Dahia, M., Mechichi, T., Hajji, M. and Nasri, M. 2015. Structural, physicochemical and antioxidant properties of sodiumalginte isolated from a Tunisian brown seaweed. - Inter. J. Bio. Macro. 72: 1358-1367.

Sengor, G.F., Cihaner, A., Erkan, N., Ozden, O. and Varlik, C. 2002. Caviar production from flathead grey mullet (Mugil cephalus) and the determination of its chemical composition and roe yield. - Turk. J. Vet. Ani. 26: 183-187.

Yang, C., Chung, D. and You, S. 2008. Determination of physicochemical properties of sulphated fucans from sporophyll of Undaria pinnatifida using light scattering technique. - Food Chem. 111: 503-507.

Yasemen, Y., Celik, M. and Akamca, E. 2005. Effects of brine concentration on shelf life of hot smoked tilapia (Oreochromis niloticus) stored at $4^{\circ} \mathrm{C}$. - Food Chem. 97: 244-247.

Yildiz, P.O. 2016. Effect of thyme and rosemary essential oils on the shelf-life of marinated rainbow trout. $-\mathrm{J}$. Ani. Plant. Sci. 26: 665-673.

Yilmaz, M., Ceylan, Z.G., Kocaman, M., Kaya, M. and Yilmaz, H. 2009. The effect of vacuum and modified atmosphere packaging on growth of Listeria in rainbow trout (Oncorhynchus mykiss) fillets. - J. Musc. Food. 20: 465-477.

How to cite this article:

Kordjazi, M., Mirsadeghi, S.H. and Asadi Farsani, O. 2019. The effect of alginate extracted from brown algae Sargassum ilicifolium on the shelf life of rainbow trout roe. - Nova Biol. Reperta 6: 155-168.

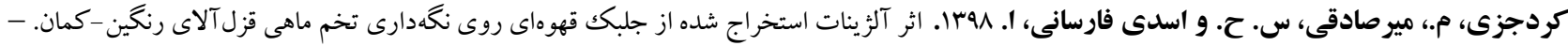
يافتهاى نوين در علوم زيستى 9: 191-1ها.
} 